\title{
CARM1 methylates MED12 to regulate its RNA-binding ability
}

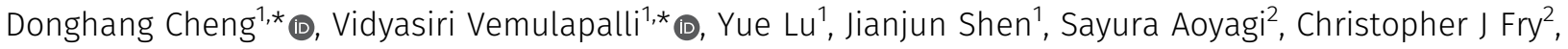 \\ Yanzhong Yang ${ }^{3}$, Charles E Foulds ${ }^{4,5}$, Fabio Stossi', Lindsey S Treviño ${ }^{5}$, Michael A Mancini ${ }^{4}$, Bert W O'Malley ${ }^{4} \mathbb{0}$, \\ Cheryl L Walker ${ }^{5}$, Thomas G Boyer ${ }^{6}$, Mark T Bedford ${ }^{1}$ (i)
}

The coactivator-associated arginine methyltransferase (CARM1) functions as a regulator of transcription by methylating a diverse array of substrates. To broaden our understanding of CARM1's mechanistic actions, we sought to identify additional substrates for this enzyme. To do this, we generated CARM1 substrate motif antibodies, and used immunoprecipitation coupled with mass spectrometry to identify cellular targets of CARM1, including mediator complex subunit 12 (MED12) and the lysine methyltransferase KMT2D. Both of these proteins are implicated in enhancer function. We identified the major CARM1-mediated MED12 methylation site as arginine $1899\left(R^{1899}\right)$, which interacts with the Tudor domain-containing effector molecule, TDRD3. Chromatin immunoprecipitation-seq studies revealed that CARM1 and the methyl mark it deposits are tightly associated with $E R \alpha$-specific enhancers and positively modulate transcription of estrogen-regulated genes. In addition, we showed that the methylation of MED12, at the $\mathrm{R}^{1899}$ site, and the recruitment of TDRD3 by this methylated motif are critical for the ability of MED12 to interact with activating noncoding RNAs.

DOI 10.26508/Isa.201800117 | Received 25 June 2018 | Revised 6 September 2018 | Accepted 7 September 2018 | Published online 19 September 2018

\section{Introduction}

Arginine methylation is a prevalent posttranslational modification, and roughly $0.5 \%$ of arginine residues are methylated in MEFs (Dhar et al, 2013). This modification has been implicated in a myriad of biological processes such as transcription, splicing, signal transduction, and DNA repair (Yang \& Bedford, 2013). Arginine methylation is catalyzed by a group of nine protein arginine methyltransferases (PRMTs), which can be classified into three types: type I (PRMT1, 2, 3, 4, 6 , and 8 ) enzymes generate $\omega-N^{G}, N^{G}$-asymmetric dimethylarginine (ADMA), type II (PRMT5 and 9) enzymes generate $\omega-N^{G}, N^{\prime G}$-symmetric dimethylarginine (SDMA), and type III (PRMT7) enzyme forms $\omega-N^{G}$ monomethyl arginine residues in mammalian cells (Bedford \& Clarke, 2009; Yang et al, 2015).

Coactivator-associated arginine methyltransferase (CARM1), which is also referred to as PRMT4, was first identified in a yeast two-hybrid screen for GRIP1-binding proteins (Chen et al, 1999). The recruitment of CARM1 to transcriptional promoters results in the methylation of the p160 coactivator family (SRC-1/NCOA1, SRC-2/GRIP1/NCOA2, and SRC-3/ NCOA3), the histone acetyltransferases (p300/CREB-binding protein [CBP]), and the histone H3 (H3R17me2a and H3R26me2a) (Chen et al, 1999; Lee et al, 2005; Feng et al, 2006). These methylation events enhance gene activation; therefore, CARM1 is considered a secondary coactivator for nuclear receptor-mediated transcription. In addition, CARM1 was also shown to coactivate NF-KB (Covic et al, 2005). Furthermore, H3R17me2a chromatin immunoprecipitation (ChIP) studies showed elevated levels at a number of gene promoters including pS2/ TFF1, E2F1, CCNE1, aP2/FABP4, Oct4, Sox2, CITED2, and Scn3b (Bauer et al, 2002; El Messaoudi et al, 2006; Frietze et al, 2008; Kleinschmidt et al, 2008; Yadav et al, 2008; Wu et al, 2009; Carascossa et al, 2010; O'Brien et al, 2010). CARM1 thus functions as a rather general transcriptional coactivator. Gene ablation studies in mice revealed that CARM1 is vital for existence (Yadav et al, 2003). Although CARM1 KO embryos are smaller in size, they are outwardly developmentally normal. These null embryos do display a number of cell differentiation defects, such as a partial block in T-cell development (Kim et al, 2004) and improper differentiation of lung alveolar cells (O'Brien et al, 2010) and adipocytes (Yadav et al, 2008). Enzyme-dead CARM1 knock-in mice phenocopy the null mice, indicating that CARM1's enzymatic activity is required for most of its in vivo functions (Kim et al, 2010). Thus, detailed knowledge of the spectrum of proteins that are methylated by CARM1 is critical for an in-depth understanding of how this enzyme regulates transcription in these different settings.

Substrate screening efforts by our laboratory and others have revealed two major classes of proteins that are methylated by

\footnotetext{
${ }^{1}$ Department of Epigenetics and Molecular Carcinogenesis, MD Anderson Cancer Center, The University of Texas, Smithville, TX, USA ${ }^{2}$ Cell Signaling Technology Inc., Danvers, MA, USA ${ }^{3}$ Department of Cancer Genetics and Epigenetics, Beckman Research Institute at City of Hope, Duarte, CA, USA ${ }^{4}$ Department of Molecular and Cellular Biology, Baylor College of Medicine, Houston, TX, USA ${ }^{5}$ Center for Precision Environmental Health, Baylor College of Medicine, Houston, TX, USA ${ }^{6}$ Department of Molecular Medicine, Institute of Biotechnology, University of Texas Health Science Center at San Antonio, San Antonio, TX, USA
} 
CARM1: RNA-binding proteins and components of the transcriptional regulatory machinery. Large-scale enzyme reactions performed on high-density protein macroarrays led to the discovery of CARM1 substrates, such as the poly-A binding protein (PABP1) (Lee \& Bedford, 2002). Using a small pool screening approach, splicing factors (SmB, SAP49, and U1C) and the transcription elongation factor (CA150) were identified as CARM1 substrates (Cheng et al, 2007). The RNA-binding proteins HuR and HuD (Li et al, 2002; Fujiwara et al, 2006) were identified by candidate approaches, as were other classes of proteins, including transcription factors (Sox2, Sox9, and Pax7) (Ito et al, 2009; Zhao et al, 2011; Kawabe et al, 2012), transcriptional coactivators including the SRCs and p300/CBP (Chen et al, 2000; Lee et al, 2005; Feng et al, 2006), and RNA Polymerase II C-terminal domain (Sims et al, 2011). Most PRMTs (PRMT1, 3, 5, 6, and 8) recognize and methylate a glycine and arginine-rich (GAR) motif (Yang \& Bedford, 2013), which has facilitated the development of arginine methyl-specific antibodies that can be used to identify and help characterize substrates for this class of PRMTs. The first methyl-GAR motif antibodies (ADMA and SDMA) were developed by the Stéphane Richard laboratory and used in immunoprecipitation (IP)-coupled mass spectrometry (MS) experiments to identify novel methylated proteins (Boisvert et al, 2003). This approach has recently been expanded upon with the development of additional methyl-specific antibodies that recognize GAR-like monomethyl arginine and ADMA motifs using redundant peptide libraries with fixed methylarginine residues as antigens (Guo et al, 2014). An alternative (antibody-independent) approach to identifying methylated proteins is based on a modification of the "stable isotope labeling by amino acids in cell culture" (SILAC) technique, called heavy methyl SILAC (Ong et al, 2004). Heavy methyl SILAC exploits the fact that methionine is taken up by the cell and converted to the sole biological methyl donor, AdoMet. Thus, if $\left[{ }^{13} \mathrm{CD}_{3}\right]$ methionine is used in these experiments, heavy methyl groups are incorporated into in vivo methylated proteins. Using this approach, in combination with methylarginine enrichment techniques, a large number of PRMT substrates were identified, including the mediator complex subunit 12 (MED12) (Uhlmann et al, 2012; Geoghegan et al, 2015). Subsequently, using ADMA antibodies, we identified MED12 as a heavily methylated protein (Guo et al, 2014), and Wei Xu's group further identified MED12 as a CARM1 substrate (Wang et al, 2015; Shishkova et al, 2017). Recently, the arginine demethylase JMJD6 was shown to interact with MED12 where it may counteract the activity of CARM1 (Gao et al, 2018).

Importantly, CARM1 has unique substrate specificity, and it does not methylate GAR motifs (Lee \& Bedford, 2002; Cheng et al, 2007). Thus, to facilitate the rapid identification of new CARM1 substrates, we developed CARM1-motif antibody screening strategies to enrich for CARM1-methylated proteins. This approach is based on the finding that the H3R17me2a antibody (Millipore), which was raised against the asymmetric dimethyl arginine 17 mark on histone $\mathrm{H} 3$, cross-reacts with a number of CARM1 substrates when used for Western blotting protein extracts from WT and CARM1 KO embryos (Yadav et al, 2003; Cheng et al, 2012). These proteins were further confirmed to be CARM1 substrates (Cheng et al, 2007). Hence, we speculated that CARM1-methylated motifs have a rather loose consensus sequence and can be used to raise pan antibodies that would potentially recognize unknown CARM1 substrates. Using a cocktail of CARM1 methylated motifs as an antigen, we demonstrate that CARM1-motif antibodies can be developed. Furthermore, we identified KMT2D, G-protein pathway suppressor 2 (GPS2), and SLM2 as new CARM1 substrates, as well as a number of previously characterized CARM1 substrates, such as MED12.

Here, we confirmed that MED12 is methylated by CARM1 at R ${ }^{1899}$ in a nonredundant manner, and demonstrated that arginine methylation of MED12 positively regulates transcription of estrogenregulated genes. To define the mechanistic basis for this effect, we found that the MED12- $\mathrm{R}^{1899 m e 2 a}$ mark serves as a docking site for the Tudor domain-containing effector molecule, TDRD3. TDRD3 is a known transcriptional coactivator that functions by recruiting topoisomerase (TOP3B) activity to chromatin (Yang et al, 2010, 2014). Importantly, we provide evidence that (1) CARM1 activity, (2) the $\mathrm{R}^{1899}$ methylation site on MED12, and (3) the recruitment of TDRD3 are all required for MED12 to bind activating long noncoding RNAs (ncRNAs)

\section{Results}

\section{Developing and characterizing CARM1 substrate motif antibodies}

Methyl-specific antibodies (both ADMA and SDMA) have previously been used to identify PRMT substrates (Boisvert et al, 2003; Guo et al, 2014; Shishkova et al, 2017). These GAR-motif antibodies likely miss many of the CARM1 substrates because CARM1 cannot methylate these motifs. Indeed, the alignment of sites of known CARM1 methylation sites does not create a clear linear motif that could be used for in silico prediction of additional candidate substrates, although the motif appears proline-rich (Cheng et al, 2007; Shishkova et al, 2017). Thus, to facilitate the identification of CARM1 substrates, a peptide cocktail of six different CARM1-methylated motifs (Fig 1A) was used to immunize rabbits to obtain four CARM1 substrate motif antibodies, henceforth referred to as ADMA ${ }^{\text {CARM1 }}$ antibodies. The four polyclonal antibodies were independently affinity purified over a column containing the six peptides.

To characterize the ADMA ${ }^{\text {CARM1 }}$ antibodies, we performed Western analysis on whole cell lysates from WT and CARM1 KO MEFs (Fig 1B). ADMA-1 ${ }^{\text {CARM1 }}$ and ADMA-2 ${ }^{\text {CARM1 }}$ recognized multiple bands in the WT lane, but displayed minimal immunoreactivity in the $\mathrm{KO}$ lane. ADMA-3 ${ }^{\text {CARM1 } 1}$ showed the loss of one band but also a slightly increased signal in the KO lane relative to the WT lane, suggesting that it might recognize proteins methylated by CARM1 and other type I PRMTs, compensating the loss of CARM1 in KO cells. ADMA$4^{\text {CARM1 }}$ seemed to be less immunoreactive than the other three antibodies, recognizing only a single CARM1 substrate. As anticipated, the H3R17me2a antibody cross-reacted with a number of proteins in WT cells, which are absent in CARM1 KO cells. Interestingly, some proteins were recognized in WT and KO cells at similar levels (indicated by asterisks). Next, we tested the antibodies on WT and PRMT1-deficient MEFs. Most proteins were recognized at similar levels in both cell lines. However, some protein bands were specific to WT cells, not PRMT1-deficient cells (indicated by solid circles) (Fig 1C). It is noteworthy that these PRMT1-specific proteins migrated at the same positions as the nonspecific proteins 
A

\begin{tabular}{|c|l|}
\hline $\begin{array}{c}\text { CARM1 } \\
\text { substrates }\end{array}$ & Methylation motifs \\
\hline PABP1 & CMPGAI (Rme2a) PAAPR \\
\hline PABP1 & CRPAAP (Rme2a) PPFST \\
\hline TARPP & CTSQQY (Rme2a) PLASV \\
\hline H3R17 & CGGKAP (Rme2a) KQLAT \\
\hline CAS3 & CAVYPV (Rme2a) SAYPQ \\
\hline CBP & CAPMGP (Rme2a) AASPM \\
\hline
\end{tabular}

D

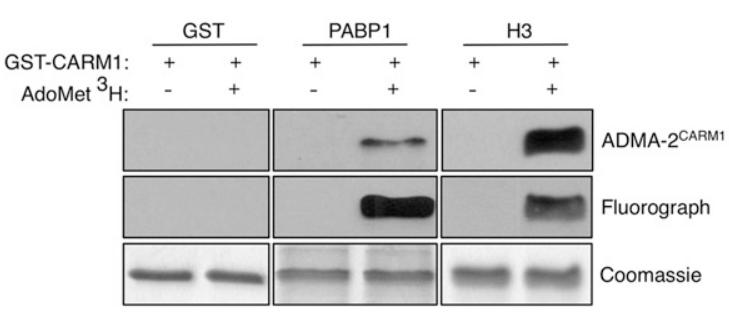

B

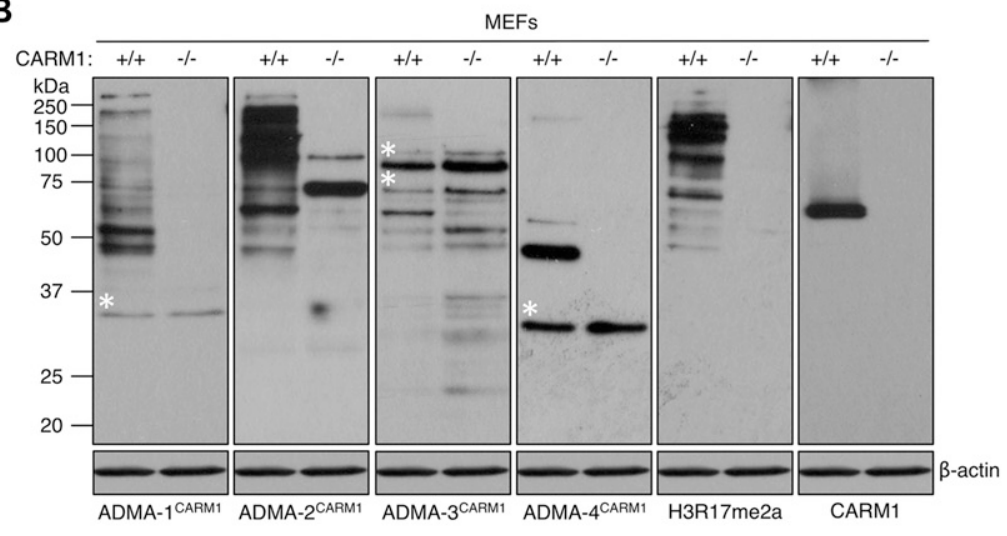

C

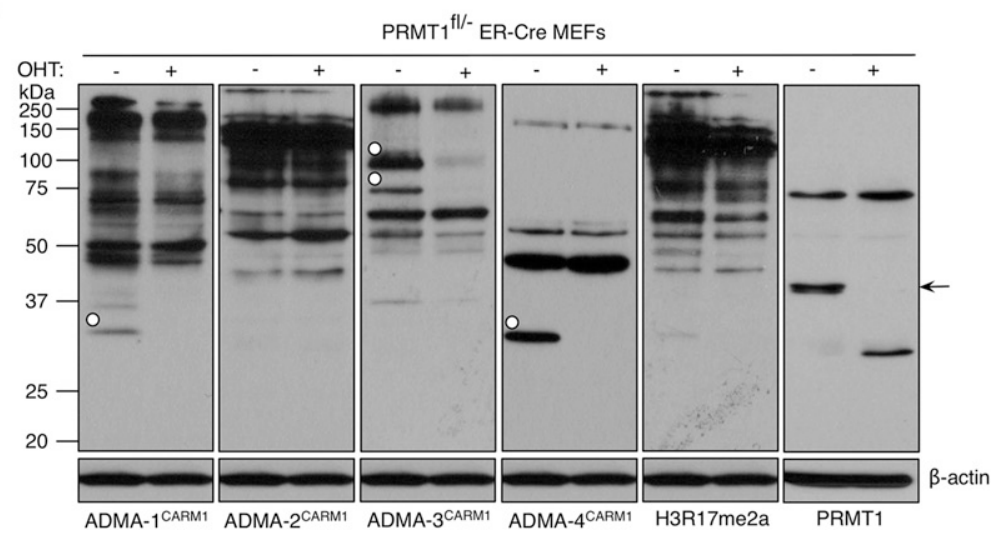

Figure 1. Characterization of CARM1 substrate antibodies.

(A) The list of six peptides used to generate CARM1 substrate antibodies. (B) Whole cell extracts from CARM1 WT (+/+) and KO (-/-) MEFs were subjected to Western analysis with $\alpha$ ADMA ${ }^{\text {CARM1 }}, \alpha$ H3R17me2a, and $\alpha$ CARM1 antibodies. The asterisks on the gels indicate the positions of the proteins present in both cell lines. $\beta$-actin serves as a loading control. (C) PRMT1 ${ }^{\mathrm{fl} /-}$ ER-Cre MEFs were untreated or treated with 4-hydroxytamoxifen (OHT, $\left.2 \mu \mathrm{M}\right)$ for $8 \mathrm{~d}$. Whole cell extracts were immunoblotted with $\alpha$ ADMA $^{\text {CARM1 }}, \alpha \mathrm{H} 3 \mathrm{R} 17 \mathrm{me} 2 \mathrm{a}$, and $\alpha$ PRMT1 antibodies. The solid circles on the gels indicate the positions of the proteins specific to PRMT1 WT (OHT-) MEFs. The arrow points to the position of the PRMT1 protein. $\beta$-actin serves as a loading control. (D) GST, PABP1, and H3 were methylated in vitro by recombinant CARM1 in the absence or presence of tritium-labeled AdoMet and subjected to Western analysis with $\alpha$ ADMA-2 ${ }^{\text {CARM1 }}$ antibody (top panel), fluorography (middle panel), and Coomassie Brilliant Blue staining (bottom panel). GST serves as a negative control.

observed in CARM1 MEFs (asterisks in Fig 1B). This suggests that although the ADMA ${ }^{\text {CARM1 }}$ antibodies primarily recognize CARM1 substrates, they can also recognize a few PRMT1 substrates.

We next tested the ability of some of the ADMA ${ }^{\text {CARM1 }}$ antibodies to recognize in vitro methylated CARM1 substrates. PABP1 and H3 were in vitro methylated by CARM1 in the absence or presence of tritiumlabeled AdoMet. Methylation efficiency was monitored by fluorography (Fig 1D, middle panel), and duplicate blots were subjected to Western blotting using the ADMA ${ }^{\text {CARM1 }}$ antibodies. We found that the ADMA-2 $2^{\text {CARM1 }}$ antibody recognized PABP1 and $\mathrm{H} 3$ in a methylspecific fashion (Fig 1D, top panel). These results confirm the establishment of a panel of four distinct rabbit polyclonal antibodies that recognize different subsets of CARM1 substrates.

\section{Using ADMA ${ }^{\text {CARM1 }}$ antibodies to identify CARM1 substrates}

A combined IP using a cocktail of the four ADMA ${ }^{\text {CARM1 }}$ antibodies and MS approach was used to identify CARM1 substrates, using an approach developed for the identification of tyrosine phosphorylation sites (Rush et al, 2005), and 112 different proteins were identified as putative CARM1 substrates. All the identified methylation sites have been submitted to the PhosphositePlus database (www. phosphosite.org). We selected 10 proteins for further evaluation based on the number of identified methylated peptides in the MS data, and the potential involvement of the candidate CARM1 substrates in different aspects of chromatin regulation, transcription, and RNA processing (Fig 2A). Of the 10 identified substrates, PABP1 (Lee \& Bedford, 2002), CA150/TCERG1 (Cheng et al, 2007), and SRC-3 (Feng et al, 2006) were described previously as in vivo CARM1 substrates, thus validating the approach. SF3B4 (Cheng et al, 2007), MED12 (Shishkova et al, 2017), SRC-1 (Feng et al, 2006), and SRC-2 (Feng et al, 2006) were previously shown to be methylated by CARM1 in vitro. GPS2, KMT2D, and SLM2 were identified as potential novel CARM1 substrates in this study. MED12 is a subunit of the mediator complex, which functions in relaying regulatory signals from transcription factor-bound enhancers to RNA Pol II (Allen \& Taatjes, 2015), and seems to be a major target for CARM1 methylation (Shishkova et al, 2017). GPS2 is an integral 
A

\begin{tabular}{|c|c|}
\hline CARM1 Substrate & Function \\
\hline $\begin{array}{c}\text { KMT2D } \\
\text { (Histone-Lysine N-methyltransferase 2D) }\end{array}$ & H3K4 mono- and trimethylation \\
\hline $\begin{array}{c}\text { GPS2 } \\
\text { (G Protein Pathway Suppressor 2) }\end{array}$ & $\begin{array}{c}\text { Component of SMRT } \\
\text { corepressor complexes }\end{array}$ \\
\hline $\begin{array}{c}\text { SLM2 } \\
\text { (Sam68-Like Mammalian 2) }\end{array}$ & RNA binding protein \\
\hline $\begin{array}{c}\text { MED12 } \\
\text { (Mediator complex subunit 12) }\end{array}$ & $\begin{array}{c}\text { Component of the Mediator } \\
\text { coregulator complex }\end{array}$ \\
\hline $\begin{array}{c}\text { SRC-1 } \\
\text { (Steroid Receptor Coactivator-1) }\end{array}$ & $\begin{array}{c}\text { Transcriptional coactivator for } \\
\text { nuclear hormone receptors }\end{array}$ \\
\hline $\begin{array}{c}\text { SRC-2 } \\
\text { (Steroid Receptor Coactivator-2) }\end{array}$ & $\begin{array}{c}\text { Transcriptional coactivator for } \\
\text { nuclear hormone receptors }\end{array}$ \\
\hline $\begin{array}{c}\text { SRC-3 } \\
\text { (Steroid Receptor Coactivator-3) }\end{array}$ & $\begin{array}{c}\text { Transcriptional coactivator for } \\
\text { nuclear hormone receptors }\end{array}$ \\
\hline $\begin{array}{c}\text { PABP1 } \\
\text { (Poly(A)-Binding Protein 1) }\end{array}$ & Translation initiation factor \\
\hline $\begin{array}{c}\text { TCERG1/CA150 } \\
\text { (Transcription Elongation Regulator 1) }\end{array}$ & Transcription elongation \\
\hline $\begin{array}{c}\text { SF3B4 } \\
\text { (Splicing Factor 3B, Subunit 4) }\end{array}$ & Pre-mRNA splicing \\
\hline
\end{tabular}

B

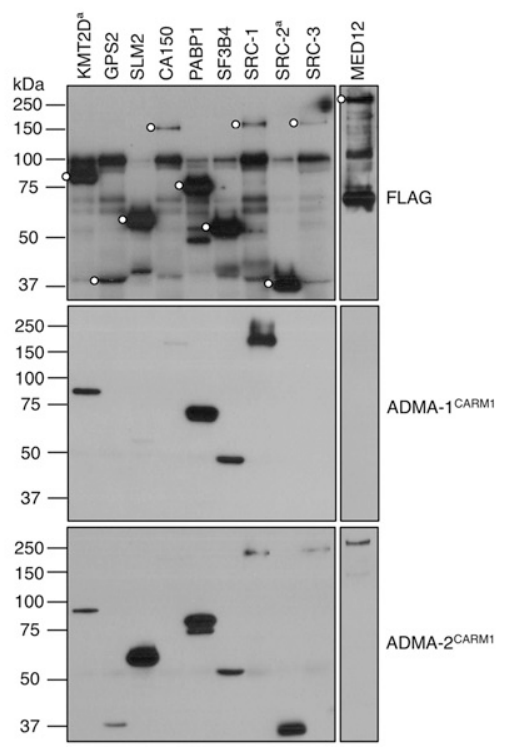

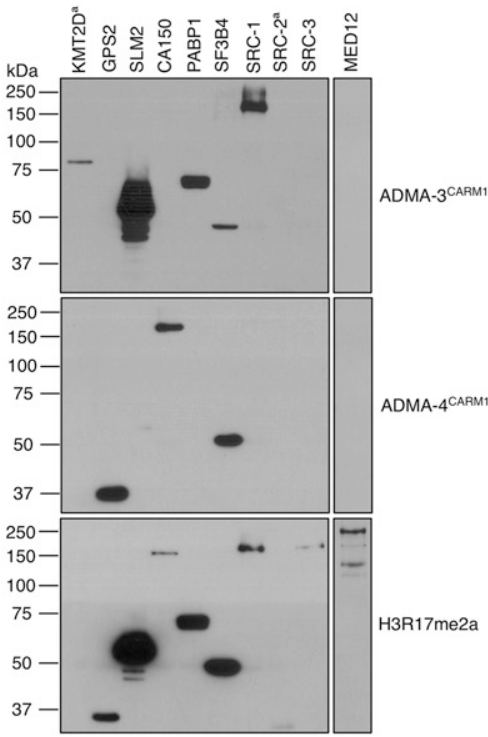

Figure 2. Identification of novel CARM1 substrates.

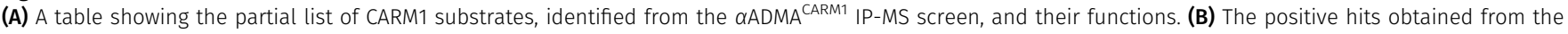
screen were transiently transfected into HEK293T cells and immunoprecipitated with $\alpha$ FLAG antibody. Western analysis was performed, first with $\alpha$ FLAG to gauge the expression of the FLAG-tagged proteins (indicated by solid circles) and then with the AADMA $^{\text {CARM1 }}$ antibodies. KMT2D ${ }^{\mathrm{a}}\left(3,619-4,285\right.$ aa) and SRC-2 ${ }^{\mathrm{a}}(1,037-1,295$ aa) represent fragments of the full-length KMT2D and SRC-2 proteins.

component of the NCOR/SMRT/HDAC3 corepressor complex (Wong et al, 2014). The mixed-lineage leukemia 4 methyltransferase (KMT2D) is responsible for depositing histone H3K4me1/2 marks at enhancers (Lee et al, 2013; Ford \& Dingwall, 2015). SLM2 is a KH domain containing protein that has been implicated in the regulation of alternative splicing (Traunmuller et al, 2014).

To confirm that the identified proteins were indeed recognized by the methyl-specific antibodies that we developed and used in the screen, we FLAG-tagged the 10 selected proteins, overexpressed them in HEK293T cells, and then immunoprecipitated them using an anti-FLAG antibody. Western analysis was performed on the immunoprecipitates, first with an anti-FLAG antibody to confirm the expression of FLAG-tagged proteins, and then with the ADMA ${ }^{\text {CARM1 }}$ antibodies (Fig 2B). Importantly, all 10 proteins were recognized by at least one of the four different ADMA ${ }^{\text {CARM1 }}$ antibodies, and no single antibody recognized all the tagged proteins. Thus, none of the four ADMA ${ }^{\text {CARM1 }}$ antibodies are totally pan CARM1 substrate antibodies, and they clearly recognize different subsets of CARM1 substrates.

In Fig $1 \mathrm{~B}$, we show that the ADMA ${ }^{\text {CARM1 }}$ antibodies primarily recognize CARM1 substrates, but they are also able to engage a few PRMT1 substrates (Fig 1C). To be sure that the new methylated proteins that we identified are indeed CARM1 and not PRMT1 substrates, we performed further analysis in CARM1 KO and knockdown cell lines that we had previously established (Yadav et al, 2003; Yang et al, 2010). We immunoprecipitated endogenous MED12 from CARM1 WT and KO MEFs, and then performed Western blot analysis using ADMA ${ }^{\text {CARM1 }}$ (and $\alpha \mathrm{H} 3 \mathrm{R} 17 \mathrm{me} 2 \mathrm{a}$ ) antibodies (Fig S1A). Both cell lines had the same amount of MED12, but only MED12 isolated from CARM1 expressing cells was immunoreactive with the two CARM1 substrate motif antibodies. These data indicate that arginine methylation of MED12 is CARM1-dependent. GPS2, KMT2D, and SLM2 were not tested in this assay, because we were unable to find specific antibodies that were able to immunoprecipitate the respective endogenous proteins. We thus overexpressed FLAGGPS2 in control and CARM1-knockdown cells, and then performed Western blotting of the FLAG immunoprecipitates using ADMA ${ }^{\text {CARM1 }}$ antibodies to show that GPS2 is specifically recognized in control cells but not in CARM1-knockdown cells (Fig S1B). In the case of KMT2D, owing to its large size (5,537 aa), we cloned a fragment $(3,619-4,285 \mathrm{aa})$ of the full-length KMT2D protein, which harbors the MS identified methylation sites (R3727 [major] and R4212 [minor]). We also engineered a R3727K mutation at this site in the FLAG-KMT2D ${ }^{a}$ construct, and found that the ADMA ${ }^{\text {CARM1 }}$ signal is significantly reduced in the R3727K-KMT2 $\mathrm{D}^{\mathrm{a}}$ mutant, relative to the WT KMT2D ${ }^{a}$ protein, indicating that R3727 is a major site for CARM1 methylation (Fig S1C and D). Finally, we also confirmed that steroid receptor coactivators SRC-1 (Fig S1E) and SRC-3 (Fig S1F) are recognized in a CARM-dependent fashion by the ADMA ${ }^{\text {CARM1 }}$ antibodies.

\section{Mediator subunit 12 is methylated at Arginine 1899 by CARM1 in vivo}

The MS studies identified MED12-R1899 as a major site of CARM1 methylation. To characterize the methylation site in more detail, we raised two independent antibodies against the MED12-R1899me2a peptide motif. Western blot analysis of CARM1 WT and KO MEF extracts showed that both antibodies detect a $240 \mathrm{kD}$ protein (the expected size of MED12) and a few other potential substrates, in a CARM1-dependent manner (Fig 3A). The meMED12 ${ }^{\text {b }}$ antibody was more selective (only recognized one additional band of about 200 $\mathrm{kD}$ ) and was used for most of the following studies. To confirm that 
the $240 \mathrm{kD}$ protein is MED12, we immunoprecipitated methylated MED12 from WT and CARM1 KO MEF lysates with the meMED12 antibodies and blotted with the MED12 (Bethyl) antibody. We found that both meMED12 antibodies selectively enriched MED12 protein from WT cells (Fig 3B). To confirm that the meMED12 antibodies are site-specific, we made a R1899K point mutation in the full-length FLAG-MED12 construct, immunoprecipitated the WT and mutant forms from transiently expressing HEK293T cells, and Western blotted with meMED12 antibody. The antibody detected the WT form of FLAG-MED12 strongly, but not the R1899K mutant form (Fig 3C). All these data clearly show that MED12 is methylated by CARM1 at R1899.

CARM1 occasionally stably interacts with its substrates (Feng et al, 2006; Kowenz-Leutz et al, 2010; Wang et al, 2014). To determine if CARM1 stably associates with the mediator complex, we performed reciprocal co-IP experiments between CARM1 and mediator subunits (MED12, MED4, MED30, and CDK8) from HeLa cell lysates. We found that CARM1 does not stably interact with the mediator complex (Fig S2A). Thus, CARM1 and MED12 are likely transiently engaged. We also tested if MED12 methylation has a role in mediator complex assembly. Co-IPS were performed between MED12 and other mediator subunits in WT and CARM1 KO MEFs. We found that the MED12 antibody co-immunoprecipitated mediator subunits (MED4, MED30, and CDK8) from WT and KO cells at similar levels. This suggests that MED12 is incorporated into the mediator complex, irrespective of its methylation status (Fig S2B).

Arginine methylated proteins, PABP1, and SAP145, are thought to be fully methylated in cells (Zeng et al, 2013; Yang et al, 2015), suggesting that these are not "regulatable" signaling nodes. To test if MED12 is fully methylated in cells, we used the tetracyclineinducible CARM1-Flp-In HEK293 cell system (Cheng et al, 2007). Upon the induction of CARM1 expression, we observed an increase in MED12 methylation levels, as detected by the meMED12 antibody (Fig 3D). On the other hand, methylated PABP1 levels did not change with CARM1 induction, as expected. Therefore, MED12 is not fully methylated in cells, and the dynamic changes in methylation levels upon CARM1 over-expression point toward a regulatory role for this R1899 methylation. Thus, transient association of CARM1 with MED12 at enhancer elements may induce local methylation of the R1899 site to facilitate the docking of a "reader" molecule.

\section{Methylated MED12 interacts with the effector molecule TDRD3}

Effector molecules for both ADMA and SDMA motifs are Tudor domain-containing proteins (Cote \& Richard, 2005; Gayatri \& Bedford, 2014). For example, the Tudor domain of SMN binds spliceosomal proteins such as SmB (Brahms et al, 2001; Friesen et al, 2001) and SAP145 (Yang et al, 2015), and TDRD3 was shown to bind the CARM1 histone code mark H3R17me2a (Yang et al, 2010). To determine if the methylated R1899 motif of MED12 interacts with any of the known methylarginine "reading" Tudor domain-containing proteins, we synthesized biotin-tagged, unmodified or methylated, MED12 peptides and validated them by an in vitro methylation assay. As expected, recombinant CARM1 methylated the unmodified MED12 peptide in vitro, but not the methylated peptide, which has no methyl-acceptor position (Fig 4A). This experiment also independently confirms that the MED12 R1899 site is indeed a CARM1 methylation motif. These peptides were then used to pull down GST-fused Tudor domains of TDRD3, SMN, SPF30, TDRKH, SPIN1, and SND1, the six best-characterized methylarginine-"reading" Tudor domain-containing proteins (Gayatri \& Bedford, 2014). Pull-down experiments demonstrated that the Tudor domain of TDRD3 bound strongly to the methylated form of the MED12 peptide, whereas SMN bound weakly (Fig 4B). Next, we endeavored to confirm that MED12 interacts with TDRD3 in cells, and that this interaction is CARM1dependent. To do this, we used CARM-inducible knockdown cells, and immunoprecipitated TDRD3 from CARM1 WT and KD cells. TDRD3 co-immunoprecipitated MED12 from WT, but not KD cells (Fig 4C). Input controls show that CARM1 was efficiently knocked-down and that MED12 methylation levels were decreased. These data establish that TDRD3 interacts with MED12 in a CARM1-dependent manner. MED12 was previously shown to be methylated by CARM1 at two additional sites (R1862 and R1912) (Wang et al, 2015). To establish the importance of all three methylation sites (R1862, R1899, and R1912) in driving the MED12-TDRD3 interactions, we transiently transfected HEK293T cells with FLAG-tagged full-length MED12, and its corresponding mutants and immunoprecipitated endogenous TDRD3 (Fig 4D). These co-IP experiments revealed that the R1862 and R1912 are not critical for this interaction, but that the R1899 site is important.

\section{Genome-wide and H3R17me2a chromatin occupancy}

To identify chromatin loci where mediator activity might be regulated by CARM1, we determined the chromatin-associated overlap of MED12, CARM1, and CARM1 activity (H3R17me2a) by ChIP-seq in MCF-7 cells. To determine the chromatin distribution of methylated MED12, we developed two methyl-specific MED12 antibodies (meMED12 ${ }^{\mathrm{a}}{ }^{\mathrm{b}}$ ), as mentioned above. In addition to methylated MED12, the antibodies recognized at least one other CARM1 substrate (Fig 3A), and are thus not ideal for ChIP experiments. The H3R17me2a antibody (Millipore) recognizes a number of different CARM1 substrates, including MED12 (Fig S1A), SRC-3 (Fig S1F), CA150 (Cheng et al, 2007), and SmB (Cheng et al, 2007). The H3R17me2a antibody is not totally pan because it does not recognize the methyl-motifs on KMT2D and SRC-2 (Fig 2B). Therefore, ChIP-seq with this antibody provides a genomic readout for most CARM1 activity, not just for the histone mark alone. From the ChIP-seq data, we detected 992 MED12 binding sites, 743 CARM1 binding sites, and 726 peaks enriched for CARM1 activity in proliferating MCF-7 cells, grown in phenol red-containing media. We observed a 33\% (410 of a total of 1,234 binding sites) overlap of the CARM1, MED12, and H3R17me2a profiles (Fig 5A). Analysis of the overlapping peaks identified a number of estrogen-regulated genes. We then compared our ChIP-seq data with the binding profiles of ER $\alpha$ and various histone modifications associated with "active" enhancers (H3K4me1 and H3K27ac), promoter (H3K4me3), and repressed (H3K27me3) regions (Fig 5B). ChIP-seq peaks from all three experiments correlate highly with functional enhancers and moderately with active promoters, but show no overlap with the repressed regions. In addition, our ChIP-seq data also displayed good overlap between H3R17me2a, active enhancer marks, and the enhancer-bound protein, MED12, which agrees with the ChIP-onchip studies performed by Myles Brown's group that reported 
A

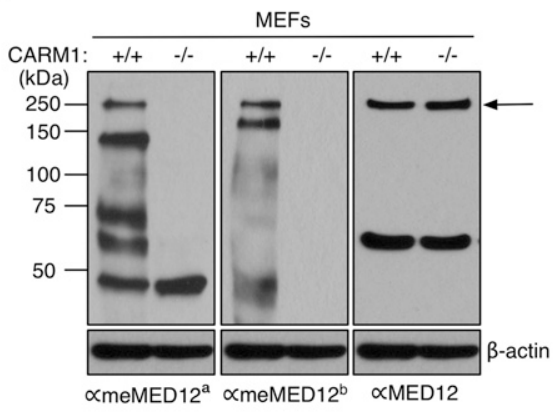

B

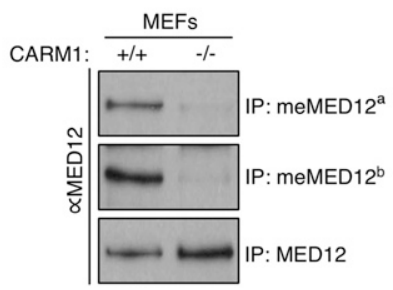

C

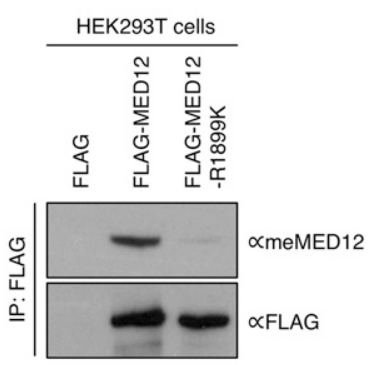

D

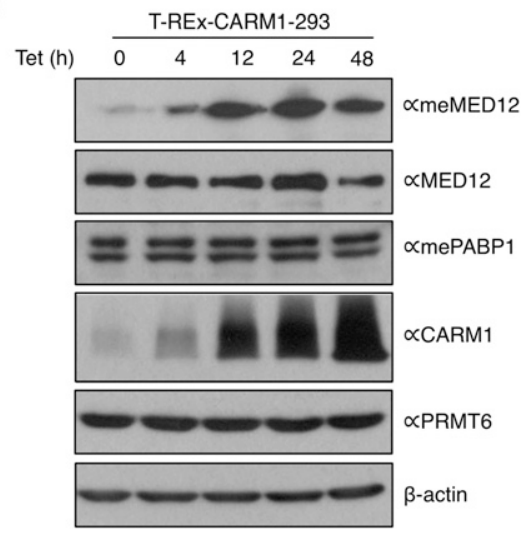

Figure 3. Characterization of two meMED12 antibodies.

(A) Whole cell extracts from CARM1 WT $(+/+)$ and KO $(-/-)$ MEFs were subjected to Western analysis with ameMED12 ${ }^{\mathrm{a}}, \alpha_{\text {meMED12 }}{ }^{\mathrm{b}}$, and $\alpha$ MED12 antibodies. The arrow points to the position of the MED12 protein. $\beta$-actin serves as a loading control. (B) CARM1 WT $(+/+)$ and $\mathrm{KO}(-/-)$ MEFs were immunoprecipitated with $\alpha$ meMED12 ${ }^{\mathrm{a}}$, $\alpha$ meMED12 ${ }^{\mathrm{b}}$, and $\alpha$ MED12 antibodies, and the eluted samples were subjected to Western blotting with $\alpha$ MED12 antibody. (C) HEK293T cells were transiently transfected with FLAG, FLAG-MED12, or FLAG-MED12-R1899K (NP_005111). Total cell lysates were immunoprecipitated with $\alpha$ FLAG antibody and the eluted samples were subjected to Western analysis with $\alpha$ meMED12 ${ }^{a}$ and $\alpha$ FLAG antibodies. (D) T-REXCARM1-293 cells were treated with tetracycline and harvested after $0,4,12,24$, and $48 \mathrm{~h}$. Whole cell extracts were immunoblotted with the indicated antibodies. $\beta$-actin serves as a loading control.
CARM1 activity predominantly at enhancer regions in MCF-7 cells (Lupien et al, 2009). Importantly, $60 \%$ of the peaks co-occupied by CARM1, MED12, and H3R17me2a (category YYY) overlap with ER $\alpha$ peaks, indicating that these mediator-bound regions targeted by CARM1 are ER $\alpha$-specific enhancers. The H3K27ac and H3K4me1 marks decorate the edges of active enhancers, creating a "trough" where the transcription factors and coregulators are enriched. It is in this trough that we see CARM1, MED12, CARM1 activity (H3R17me2a) and ER $\alpha$ signals (Fig 5C). In addition, motif analysis of CARM1, MED12, and CARM1 activity peaks revealed a consensus sequence that is almost identical to the canonical ER $\alpha$ binding motif (Fig 5D). It is noteworthy that a subset of peaks, which are weak in ER $\alpha$ and H3R17me2a signals, are associated with active promoters (i.e., categories YYN and YNN overlap well with the H3K4me3 signal) (Figs 5B and S3A). We speculate that these peaks may constitute a distinct class of CARM1-regulated genes that do not associate with ER $\alpha$. Indeed, motif analysis under this subset of H3K4me3 peaks identified a binding motif for Sp1 (Fig S3B), suggesting that this basal transcription factor may also make use of CARM1's coactivator activity.

To highlight the degree of co-occupancy of CARM1, MED12, and CARM1 activity at EREs, we focused on the well-characterized ER $\alpha$ target gene, GREB1, which has four well-defined EREs (Carroll et al, 2006) (Fig 6A). Similar tight overlap of these three ChIP-seq profiles is also observed at the TFF1, IGFBP4, and FKBP4 loci (Fig S4A-C). Next, five ER $\alpha$ target genes that displayed strong overlap of all three ChIPseq profiles (GREB1, TFF1, IGFBP4, FKBP4, and NOB1) were tested for their dependency on CARM1 for optimal E2-induced expression. To do this, a Tet-inducible CARM1 shRNA-knockdown MCF-7 cell line was used, and CARM1 knockdown significantly reduced the expression of all five tested genes (Fig 6B). To establish the importance of the MED12 methylation sites in this process, we generated a CRISPRmediated MED12 KO MCF7 cell line (Fig S5A-C), and rescued this cell line with WT and mutant forms of MED12-either a single mutant (SM) at R1899, or a triple mutant (TM) at R1862, 1899, and R1912. Although the reexpression of WT MED12 was able to rescue the expression of this panel of ER-regulated genes, neither of the mutant MED12 vectors were capable (Fig 6C), thus highlighting the importance of the R1899 methylation site on MED12.

\section{MED12 methylation by CARM1 regulates its ability to bind ncRNA-a}

There is emerging evidence that the mediator complex interacts directly with RNA at enhancer elements (Kim \& Shiekhattar, 2015). In particular, two studies have recently shown that the appearance of bi-directional enhancer RNAs (eRNAs) correlate with the recruitment of the mediator complex (Hsieh et al, 2014; Step et al, 2014), and siRNA knockdown of eRNA production results in reduced mediator recruitment (Hsieh et al, 2014). In addition, a direct interaction between MED12 and a class of long noncoding RNAs called activating ncRNAs (ncRNA-a) has been identified (Lai et al, 2013). Activating ncRNAs function by regulating their neighboring genes using a cis-mediated mechanism (Orom et al, 2010; Wang et al, 2011). Recently, Dlx1as has also been identified as an ncRNA-a that binds 
A

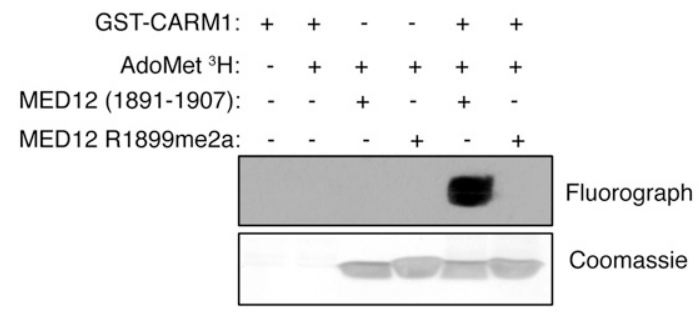

B

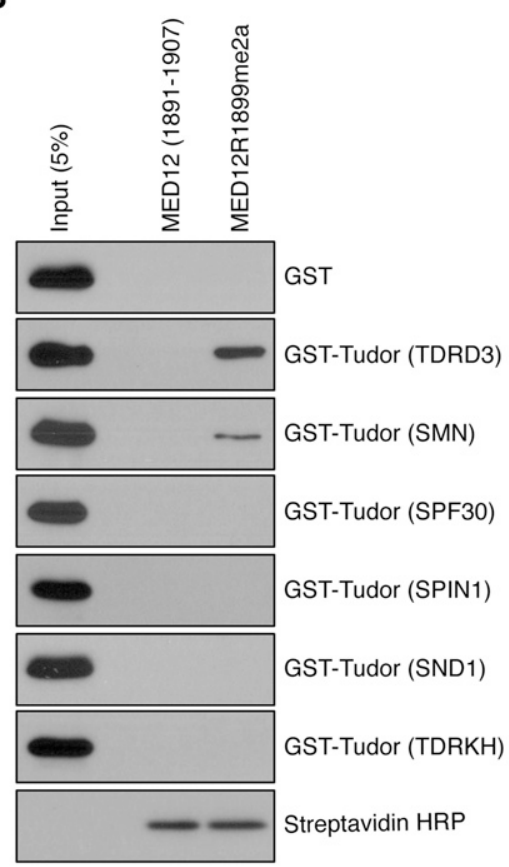

C
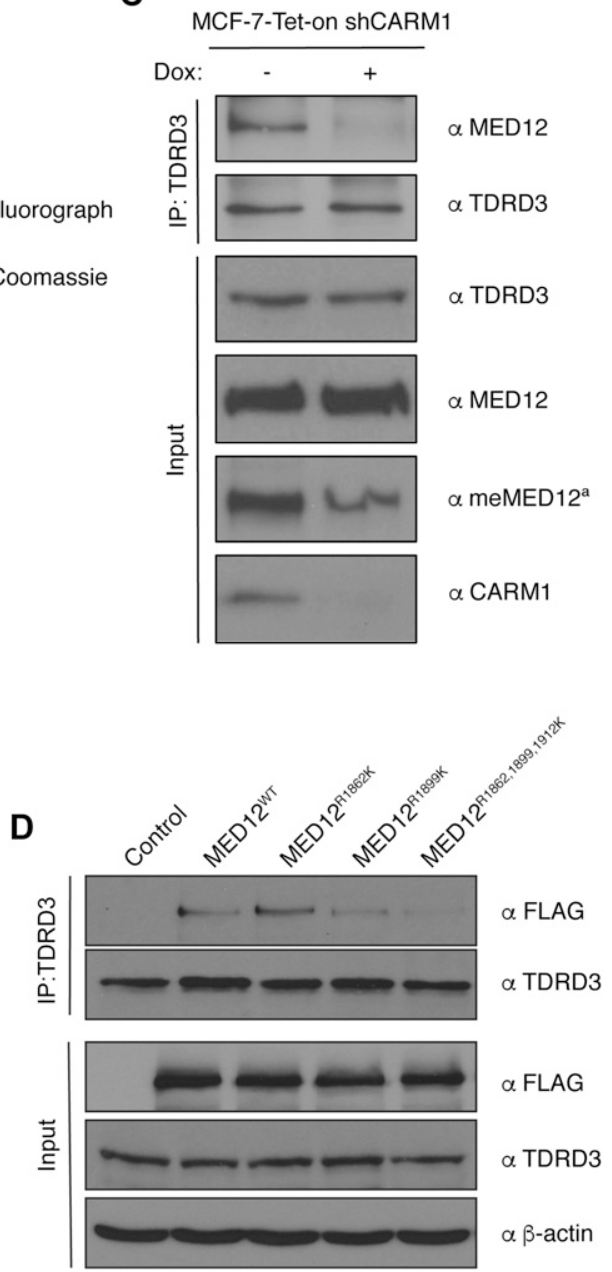

Figure 4. MED12 interacts with TDRD3 in a CARM1dependent fashion.

(A) Fluorograph (top panel) and Coomassie Brilliant Blue staining (bottom panel) of the peptides in vitro methylated by recombinant CARM1 in the presence of tritium-labeled AdoMet. (B) The peptides were used to pull down Tudor domains of the indicated proteins. The input samples and the eluted samples were immunoblotted with $\alpha \mathrm{GST}$ antibody. Streptavidin HRP serves as a peptide loading control. (C) MCF-7-Tet-onshCARM1 cells were untreated or treated with doxycycline $(1 \mu \mathrm{g} / \mathrm{ml})$ for $8 \mathrm{~d}$. Nuclear extracts were subjected to IP with $\alpha$ TDRD3 antibody and the eluted samples were detected by Western blotting with $\alpha M E D 12$ and $\alpha$ TDRD3. The input samples were immunoblotted with $\alpha$ TDRD3, $\alpha$ MED12, $\alpha$ meMED12 ${ }^{\mathrm{a}}$, and aCARM1. (D) HEK293T cells were transiently transfected with FLAG, FLAG-MED12 WT, FLAG-MED12-R1862K, FLAGMED12-R1899K, and FLAG-MED12-R1862,1899,1912K. Total cell lysates were immunoprecipitated with $\alpha$ TDRD3 antibody and the eluted samples were subjected to Western analysis with $\alpha$ FLAG and $\alpha$ TDRD3 antibodies. The input samples were immunoblotted with $\alpha$ FLAG, $\alpha$ TDRD3, and $\alpha \beta$-actin.
MED12 and controls the expression of members of the nearby HoxD gene cluster (Papadopoulou et al, 2016). To investigate whether CARM1 may regulate the MED12/nCRNA-a interactions, we performed an RNA IP (RIP) experiment with MED12 antibodies, followed by RT-qPCR. We found that a set of ncRNAs interact with MED12 in a CARM1-dependent manner (Fig 7A). Importantly, the loss of nCRNA-a interaction with MED12 in CARM1 knockdown cells is not due to decreased expression of these ncRNAs (Fig S6). Furthermore, this interaction was dependent on TDRD3 (Fig 7B), the methyl-dependent MED12 interacting protein we identified (Fig 4). Also, the MED12-R1899K mutant interacted less efficiently with the tested ncRNA-a set (Fig 7C). Interestingly, TDRD3 recruits TOP3B to not only target R-loops (Yang et al, 2014), but also unwinds RNA (Stoll et al, 2013), which may be important here. Also, TDRD3 binds directly to single-stranded RNA (Siaw et al, 2016). To test the hypothesis that CARM1 methylation of MED12 could regulate the transcription of a gene adjacent to an ncRNA-a locus, we focused on ncRNA-a5, which lies close to the well-documented CARM1-regulated ER target gene, GREB1 (Rae et al, 2005) (Fig 7D). Knockdown of ncRNA-a5, using two independent shRNAs, selectively reduces the expression of GREB1 (Fig 7E).

\section{Discussion}

CARM1 methylates an ill-defined, but distinct, proline-rich motif

Most PRMTs methylate GAR domains (Thandapani et al, 2013); CARM1 does not. When the methylation site in CARM1 substrates is aligned (Lee \& Bedford, 2002; Cheng et al, 2007; Shishkova et al, 2017), there is clearly no obvious motif, except for the propensity for proline residues in the vicinity of the CARM1 methylation site. But even the proline residues are not at a fixed position from the methylated arginine, suggesting that all that is needed is a stiff bend, on either side (or both sides) of the methylation site. Indeed, using oriented peptide arrays, a similar proline-rich methylation motif was identified for CARM1, in a totally unbiased manner (Gayatri et al, 2016). Thus, even after the identification of a number of different CARM1 substrates, the methylation motif for this enzyme still remains rather nebulous and difficult to predict based on the primary sequence. Interestingly, although it is difficult to predict a CARM1 substrate, antibodies developed to one substrate often cross-react with other substrates, so antibodies are able to identify some structural similarity between CARM1 methylation 
A

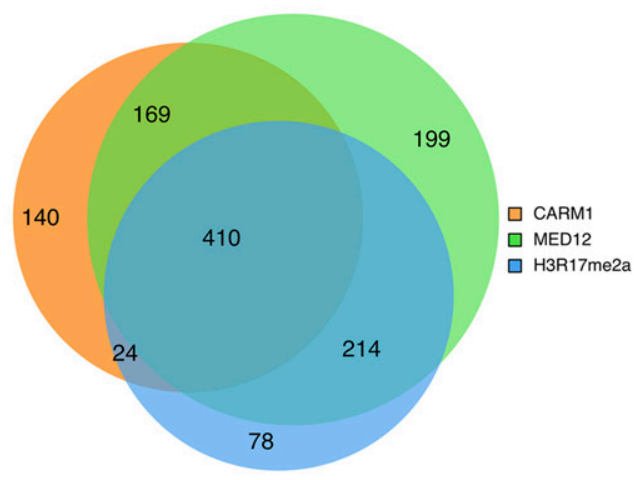

D ${ }^{2} \cdot \mathrm{C}_{\text {Canonical }} \mathrm{CR} \alpha$
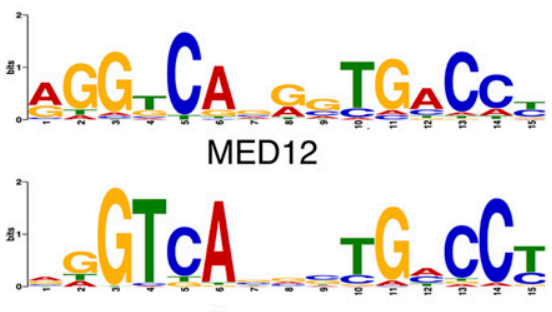

CARM1

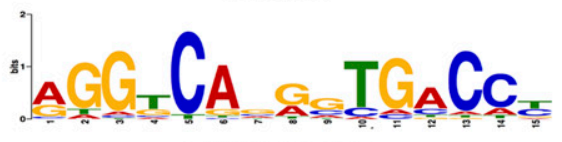

H3R17me2a
B

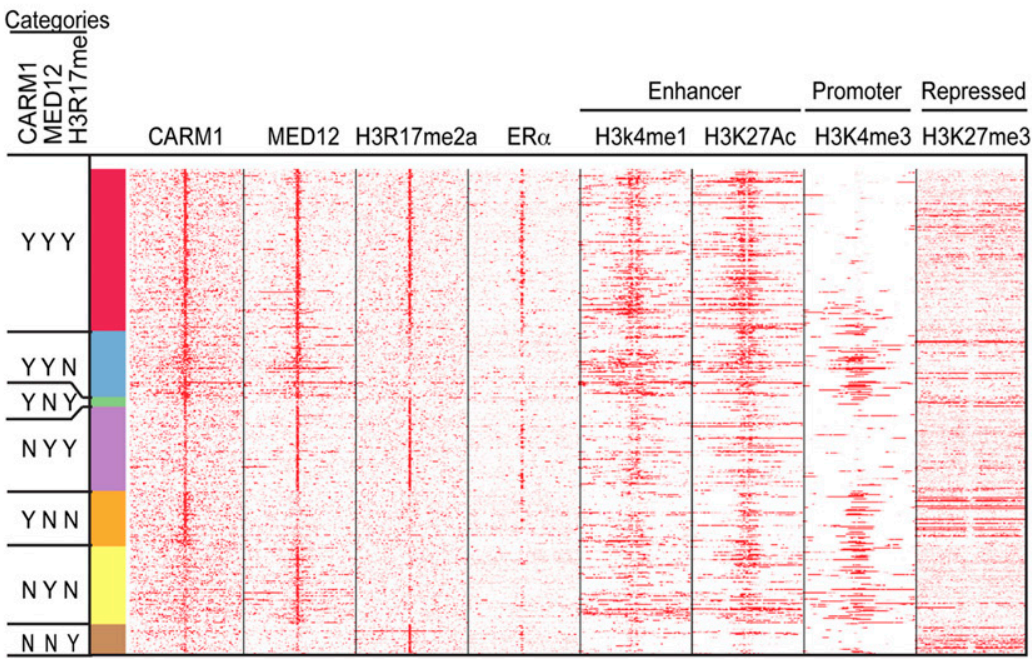

C

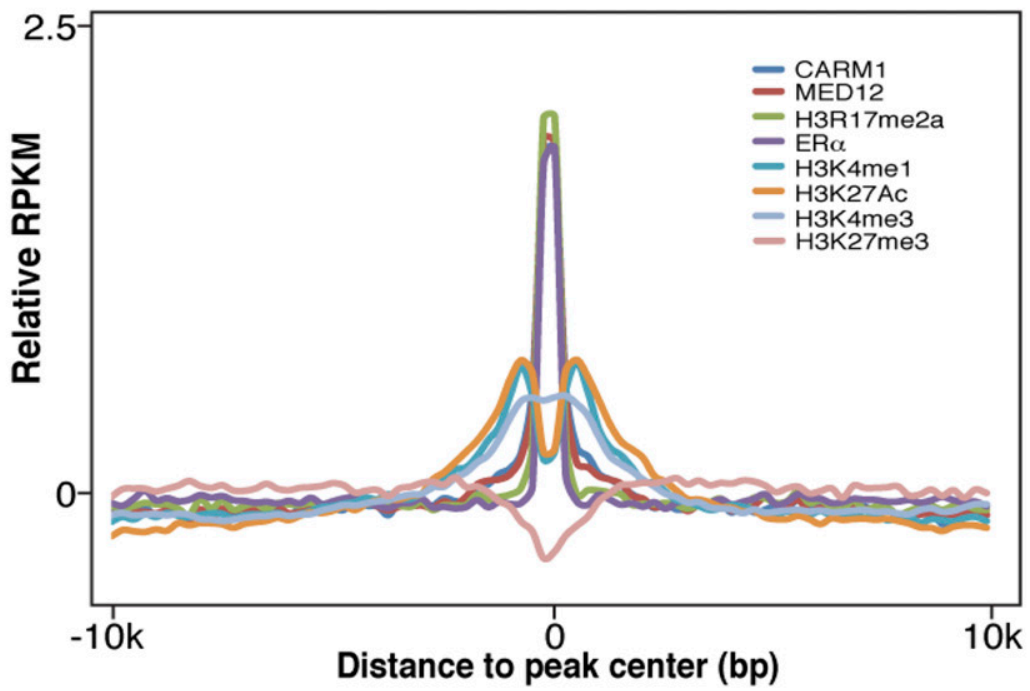

Figure 5. ChIP-seq analysis of CARM1, MED12, and H3R17me2a in MCF-7 cells.

(A) Venn diagram showing an overlap between CARM1-, MED12-, and H3R17me2a-binding sites on the MCF-7 genome. (B, C) Heatmap and distribution figures depict profiles for genome-wide localization of CARM1, MED12, H3R17me2a, ER $\alpha$, enhancer (H3K4me1 and H3K27ac), promoter (H3K4me3), and repressor (H3K27me3) marks. Categories: YYY-peaks co-occupied by CARM1, MED12, and H3R17me2a; YYN-peaks co-occupied by CARM1 and MED12; YNY-peaks co-occupied by CARM1 and H3R17me2a; NYY-peaks co-occupied by MED12 and H3R17me2a; YNN, NYN, and NNY-peaks occupied by CARM1, MED12, and H3R17me2a, respectively. (D) Comparison of the binding motifs for MED12, CARM1, H3R17me2a, and ER $\alpha$.

motifs. This "semi-pan" nature of CARM1 substrate antibodies was first realized using the $\alpha \mathrm{H} 3 \mathrm{R} 17$ me2a antibody, which we have shown recognizes SRC3 (Naeem et al, 2007) and CA150 (Cheng et al, 2007), and also recognizes GPS2, SLM2, PABP1, SF3B4, SRC1, and MED12 (Fig 2B).

Given the transient nature of CARM1-substrate interaction, it has been challenging to obtain cocrystal structures of these complexes. However, structural studies using three diverse substrate sequences provided insight into the flexibility of the CARM1 enzyme (Boriack-Sjodin et al, 2016), which were further supported using novel transition state mimics of two independent CARM1 substrate motifs (van Haren et al, 2017). These two studies revealed that the binding interactions of the peptides with CARM1 were permissive of flanking proline residues on either side of the substrate arginine. Furthermore, the conformational constraints bestowed on a peptide motif by proline residues, kinks the arginine residue into the active site.

\section{CARM1 primarily associates with enhancers, but is also found at promoters}

By exploiting the pan nature of the H3R17me2a antibody (Millipore), CARM1 activity was first mapped in a global fashion by Myles Brown's group, using a ChIP-on-chip approach (Lupien et al, 2009). They found that the majority (70\%) of ER $\alpha$ binding sites are associated with CARM1 activity. Most of the CARM1 activity mapped to intergenic and intronic regions, with less than $3 \%$ of this activity associated with proximal promoter regions. Our expanded H3R17me2a ChIP-seq data support these findings. Interestingly, recent H3R17me2a 
A

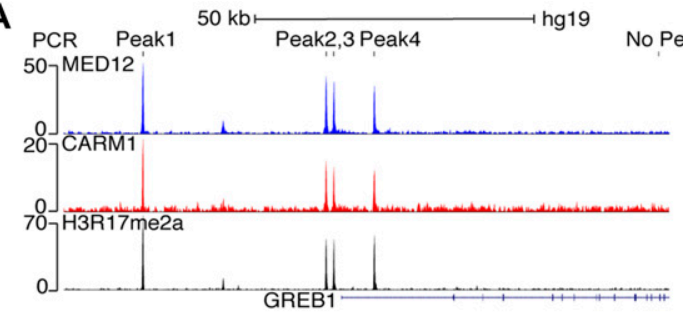

B

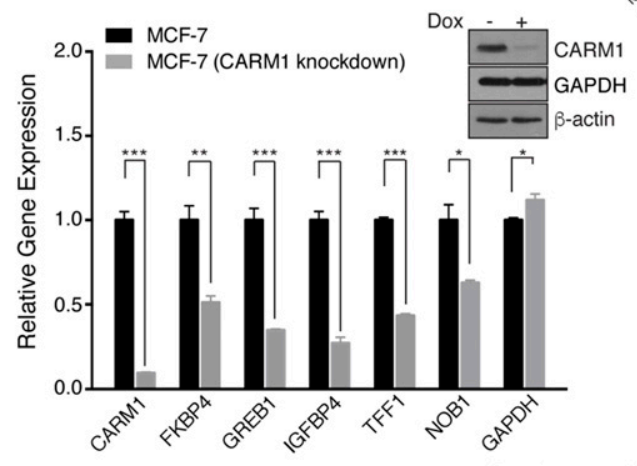

C

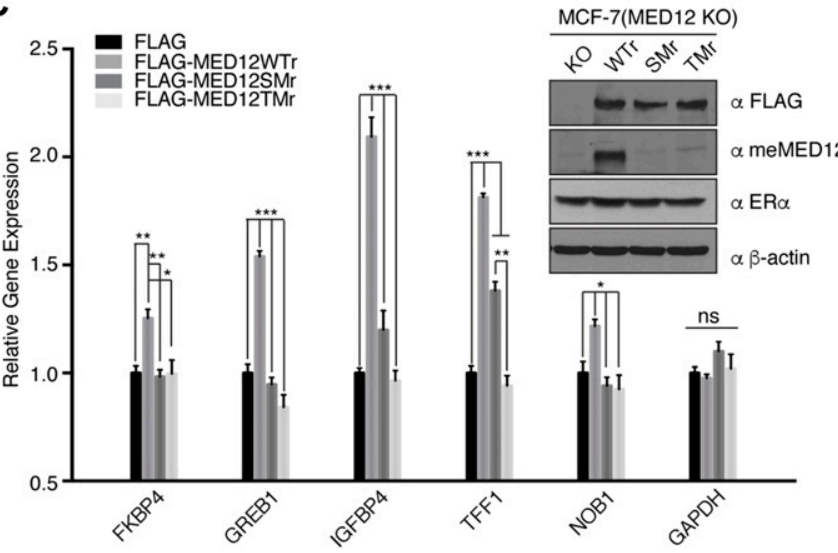

Figure 6. Regulation of ChIP-seq target genes by MED12 methylation. (A) ChIP-seq peaks demonstrating the enrichment of MED12, CARM1, and H3R17me2a signals at the GREB1 gene locus (left panel). ChIP and quantitative PCR analysis of the association of MED12, CARM1, and H3R17me2a with GREB1 gene (right panel). (B) MCF-7-Tet-on-shCARM1 cells were untreated or treated with doxycycline $(1 \mu \mathrm{g} / \mathrm{ml})$ for $8 \mathrm{~d}$. Total RNA was extracted and RT-PCR was performed using primers specific for the genes shown. GAPDH acts as a negative control. Target gene expression was normalized to $\beta$-actin. Error bars represent SD based on three independent experiments. ${ }^{*} P<0.05,{ }^{* *} P<0.01$, and ${ }^{* *} P<0.001$ ( $t$ test). (C) A rescue experiment was performed whereby WT, single (R1899K), or triple (R1862K/R1899K/R1912K) mutant FLAG-MED12 constructs were reintroduced into MED12 KO MCF-7 cells generated by CRISPR-Cas9 gene editing. These constructs (denoted by WTr, SMr, and TMr) contain five synonymous mutations in the guide sequence to prevent Cas9 cleavage. MED12 KO cells were cultured in phenol red-free DMEM supplemented with 10\% charcoal dextran-stripped FBS for $3 \mathrm{~d}$ before transfection, and then treated with E2 (50 nM) for $24 \mathrm{~h}$. Total RNA was extracted and RT-qPCR was performed using primers specific for the genes shown. Target gene expression was normalized to $\beta$-actin. Inset figures show similar expression levels of the WT and mutant proteins. Error bars represent SD based on three independent experiments. ${ }^{*} P<0.05,{ }^{* *} P<0.01$, and ${ }^{* * *} P<0.001$ ( $t$ test)

ChIP-seq experiments using an antibody from Abcam, mapped CARM1 activity to promoter regions in MEFs (Shin et al, 2016). These disparities could be due to the different cell types (MCF7 versus MEF) or antibodies used in the different experiments. Importantly, the two independently sourced H3R17me2a antibodies (Millipore and Abcam) both recognize many CARM1 substrates when tested by Western blot on total cell lysates (Fig S7), so clearly, neither antibody can be used to identify the chromatin localization of the H3R17me2a histone mark, without recognizing other CARM1 substrates.

The association of CARM1 itself with chromatin has been investigated using a reChIP-on-chip approach (Coughlan et al, 2013). In this study from Joe Torchia's group, a promoter array was used for the profiling, so they were not able to investigate enhancer enrichment of CARM1. However, the SRC3/CARM1 protein complex associated not only with promoter proximal EREs, but also with Sp1 and C/EBP $\alpha$ binding motifs (Coughlan et al, 2013). Importantly, the Sp1 motif is enriched in the YYN and YNN clusters that are associated with CARM1 activity at promoters that are also marked with H3K4me3 signal (Figs 5B and S3). We did not observe enrichment for the $\mathrm{C} / \mathrm{EBP} \alpha$ motif in our ChIP-seq experiment. The reChIP-on-chip experiment focused on identifying promoters that recruited CARM1 through its association with SRC3 (Coughlan et al, 2013). This is likely just a subset of promoters that are engaged by CARM1 because it can be recruited by other SRCS and also directly by other transcription factors themselves. Indeed, CARM1 interacts directly with $E R \alpha$ (without the help of SRCS) in response to CAMP signaling (Carascossa et al, 2010), and also with c-Fos (Fauquier et al, 2008) and C/EBP $\beta$ (Kowenz-Leutz et al, 2010). CARM1 not only binds, but also methylates $C$ /EBP $\beta$ and inhibits the association of this transcription factor with the mediator complex (Kowenz-Leutz et al, 2010). NF-KB is another transcription factor that directly interacts with CARM1 (Covic et al, 2005), and it was later reported that CARM1 is present at the promoter/enhancer looping joint of a NF-kBregulated gene (MCP-1) (Teferedegne et al, 2006). In this setting, CARM1 was not required for looping, but was required for efficient expression of MCP-1. CARM1 also binds directly to the Notch intracellular domain, and can be detected at the notch intracellular domain-bound enhancer sites of a number of notch target genes (Hein et al, 2015). Thus, CARM1 is not a dedicated ER $\alpha$ coactivator, but is also recruited by other transcription factors to both proximal promoters and enhancer elements.

CARM1 is not only recruited to chromatin by transcription factors, but also by ATP-dependent remodeling complexes, including the SWI/SNF complex (Xu et al, 2004; Wang et al, 2014), and directly interacts with the Mi2 $\alpha$ and Mi2 $\beta$, components of the NuRD complex (Streubel et al, 2013). Although NuRD is generally considered a transcriptional repressor complex, there is emerging evidence that it can also positively regulate gene expression, particularly in light of recent genomic localization studies that show its enrichment at active promoters and enhancers (Shimbo et al, 2013).

At both enhancer elements and at some proximal promoters, CARM1 methylates a host of different proteins that are detected with the H3R17me2a antibody. However, it is clear that the H3R17me2a Millipore antibody does not recognize all CARM1 substrates (Fig 2B-KMT2D and SRC2). This is supported by our ChIP-seq data showing two categories (YYN and YNN) that display strong CARM1 recruitment, but very little H3R17me2a antibody ChIP signals (Fig 5B). It is likely that CARM1 activity at these proximal promoter regions will be detected using a different CARM1 substrate antibody. These data support the idea of distinct methylarginine "fingerprints" on transcriptional coactivators at different gene promoters and enhancers, 
A

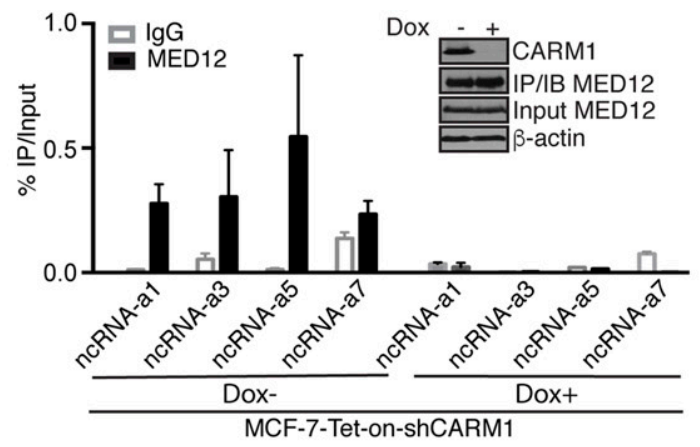

B

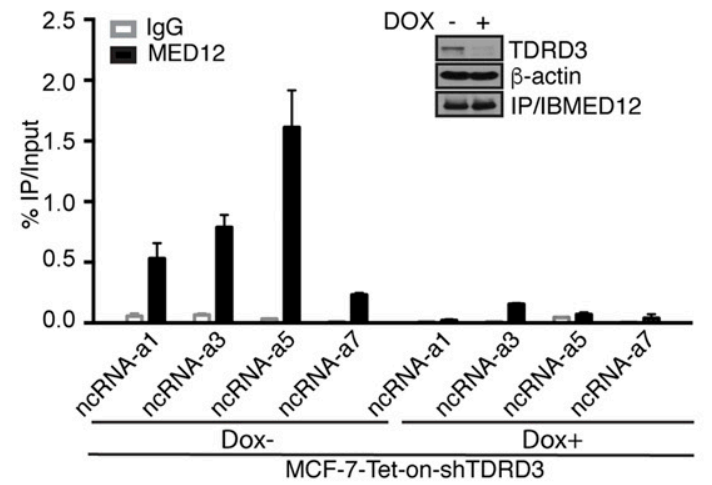

C

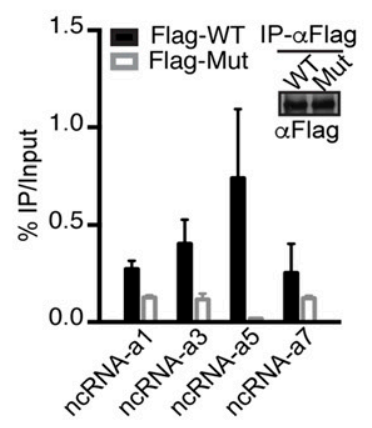

D

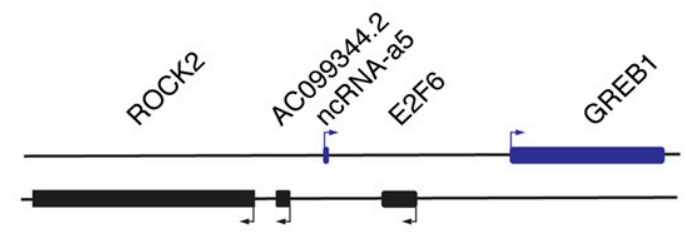

E

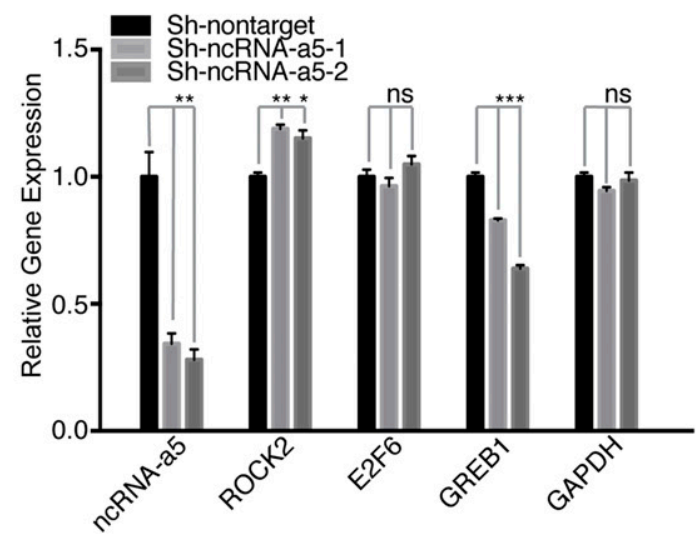

which was first proposed by the Gronemeyer group (Ceschin et al, 2011). In that study, they showed that three methyl-specific antibodies, raised against different CARM1 methylation sites on the CBP, displayed dissimilar localization signatures at different EREs. In a similar way, it is possible that MED12, which has at least three prominent CARM1 methylation sites (R1862, R1899, and R1912), will also be modified in different combinations to exert different MED12 functions.

\section{How does CARM1 methylation of MED12 regulate its function?}

MED12 has cytoplasmic and nuclear functions. In the cytoplasm, it regulates the TGF- $\beta$ R2 pathway (Huang et al, 2012). Methylation of MED12 by CARM1 at R1862 and R1912 regulates its cytoplasmic functions (Wang et al, 2015). We demonstrate here that methylation of MED12 at R1899 regulates a subset of its nuclear functions, and provides an additional level of gene expression regulation governed by CARM1. Although the mediator complex broadly regulates transcription, the MED12 subunit is only partially methylated in cells (Fig 3D), suggesting that the mediator complex targeted by CARM1 may regulate a specific set of transcriptional programs, as opposed to all RNA Pol II-dependent genes. From ChIP-seq experiments, we defined this specific set of genes to be ER $\alpha$-dependent and confirmed, by gene expression studies, that MED12 methylation enhanced the transcriptional activation of these genes (Fig 6B and C).

Methylation of MED12 signals the recruitment of TDRD3, which may promote transcriptional activation because of TDRD3's coactivator activity (Yang et al, 2010). TDRD3 is in a tightly bound complex with the topoisomerase, TOP3B (Stoll et al, 2013; Yang et al, 2014). It has been shown that the TDRD3/TOP3B complex is recruited to active chromatin through the ability of the TDRD3 Tudor domain to interact with the H3R17me2a and H4R3me2a marks (Yang et al, 2014), and the C-terminal domain of RNA Polymerase II (Sims et al, 2011). Here, we report a third mark that is "read" by TDRD3: MED12R1899me2a. The recruitment of the TDRD3/TOP3B complex to this motif could help resolve R-loops at sites of active transcription (Yang et al, 2014), or it could act on ncRNA molecules that are associated with the mediator complex. Indeed, TOP3B was recently shown to possess both DNA

Figure 7. MED12 association with ncRNA-a is disrupted by loss of CARM1 and TDRD3.

(A) MCF-7-Tet-on-shCARM1 cells were untreated or treated with doxycycline $(1 \mu \mathrm{g} / \mathrm{ml})$ for $8 \mathrm{~d}$ to knockdown CARM1 (see inset). Lysates were subjected to UV-RIP using IgG or MED12 antibodies and analyzed by RT-qPCR with primers specific for the indicated ncRNA-a. Error bars represent SD based on replicates $(n=3)$. (B) MCF-7-Tet-on-shTDRD3 cells were induced with doxycycline $(1 \mu \mathrm{g} / \mathrm{ml})$ for $8 \mathrm{~d}$ to knockdown TDRD3 (see inset). The cells were subjected to UV crosslinking followed by RNA IP (UV-RIP) using IgG or MED12 antibody and analyzed by RT-qPCR with primers specific for the indicated nCRNA-a. Error bars represent SD based on replicates $(n=3)$. (c) HEK293T cells transiently expressing FLAG-MED12 (WT) or FLAG-MED12R1899K (Mut) were UV crosslinked, lysed, and incubated with FLAG antibody. The immunoprecipitated RNAs were then analyzed by RT-qPCR to assess ncRNA-a levels. Inset shows similar immunoprecipitated levels of WT and Mut proteins. (D) ncRNA-a5 is located near GREB1 on human chromosome 2p25.1, along with E2F6 and ROCK2 genes. (E) Knockdown of ncRNA-a5 results in reduced expression of GREB1, as gauged by RT-qPCR. This experiment was performed in MCF-7 cells induced with E2 for $4 \mathrm{~h}$ prior to RNA isolation. RT-qPCR was performed using primers specific for the genes shown. Target gene expression was normalized to $\beta$-actin. Error bars represent SD based on three independent experiments. ${ }^{*} P<0.05,{ }^{* *} P<0.01$, and ${ }^{* * *} P<0.001$ ( $t$ test). 
and RNA topoisomerase activities (Xu et al, 2013; Yang et al, 2014; Siaw et al, 2016). Importantly, the mediator has been shown to associate with at least two classes of noncoding RNAs: (1) activator RNAs that increase the transcription of neighboring genes (Lai et al, 2013) and (2) eRNAs that correlate with enhancer-promoter looping and gene activation (Hsieh et al, 2014). The recruitment of the TDRD3/TOP3B complex, and its dual topoisomerase activity, may be required for not only reducing R-loop formation in the wake of Pol II at active genes, but also for the "untangling" and "correct" structural presentation of these RNA scaffolds for efficient MED12 binding, at sites of enhancer-promoter looping (Fig 8).

\section{Materials and Methods}

\section{Antibodies}

CARM1 substrate motif antibodies were raised against an antigen mixture of six different CARM1 methylated motifs (Fig 1A), to specifically recognize endogenous proteins when asymmetrically dimethylated by CARM1. The meMED12 antibodies were raised against the peptide sequence $T_{S V Y R}{ }^{*} Q Q Q P$ of human MED12 protein (NP_005111). This work was performed in collaboration with Cell Signaling Technology (CST). mePABP1 antibody was raised against the peptide sequence CGAIR*PAAPR*PPFS of human PABP1 protein (NP_002559) (Cheng \& Bedford, 2011). $R^{*}$ denotes asymmetrically dimethylated arginine residue. The MED4, MED30, and CDK8 antibodies were a gift from Thomas Boyer (University of Texas Health Science Center at San Antonio). The CARM1 antibody, used for ChIP-seq, was a gift from Stéphane Richard (McGill University). The following antibodies were obtained commercially: H3R17me2a (07-214; Millipore and ab8284; Abcam), MED12 (A300-774A; Bethyl), SRC-1 (2191; CST), SRC-3/AIB1 (611105; BD Transduction), CARM1 (A300-420A; Bethyl), PRMT1 (A300722A; Bethyl), PRMT6 (A300-929A; Bethyl), CDK8 (SC-1521; Santa Cruz), and FLAG (F7425 [rabbit IgG] and F3165 [mouse IgG]; Sigma-Aldrich).

\section{Plasmids and peptides}

GST-PABP1 (Lee \& Bedford, 2002), GST-CARM1 (Frankel et al, 2002), FLAG-CA150 (Cheng et al, 2007), GST-Tudor (TDRD3) (Yang et al, 2010), and GST-Tudor (SMN) (Kim et al, 2006) have been described previously. The other GST-Tudor constructs used in the pull-down experiments were generated by cloning the Tudor domains of SPF30, SPIN1, SND1, and TDRKH, separately, into a pGEX-6p-1 vector (Biomatik). Recombinant $\mathrm{H} 3$ protein used in the in vitro methylation assay was purchased from New England Biolabs. The siRNAresistant P3XFLAG-MED12r plasmid was a gift from Thomas Boyer (University of Texas Health Science Center at San Antonio). The KMT2D ${ }^{a}$ fragment $(3,619-4,285$ aa) was amplified from human CDNA using gene-specific primers and subcloned into a p3XFLAG-CMV-7.1 vector. FLAG-GPS2 was a gift from Darryl Zeldin (NIEHS). SLM2 CDNA was a gift from Stéphane Richard (McGill University). FLAG-PABP1 and FLAG-SF3B4 were generated by cloning the CDNAs from GSTPABP1 and His-SF3B4 (Lee \& Bedford, 2002; Cheng et al, 2007). SRC-1, SRC2, and SRC-3 constructs were kindly provided by Bert O'Malley (Baylor College of Medicine). FLAG-MED12-R1899K and FLAG-KMT2Da-R3727K

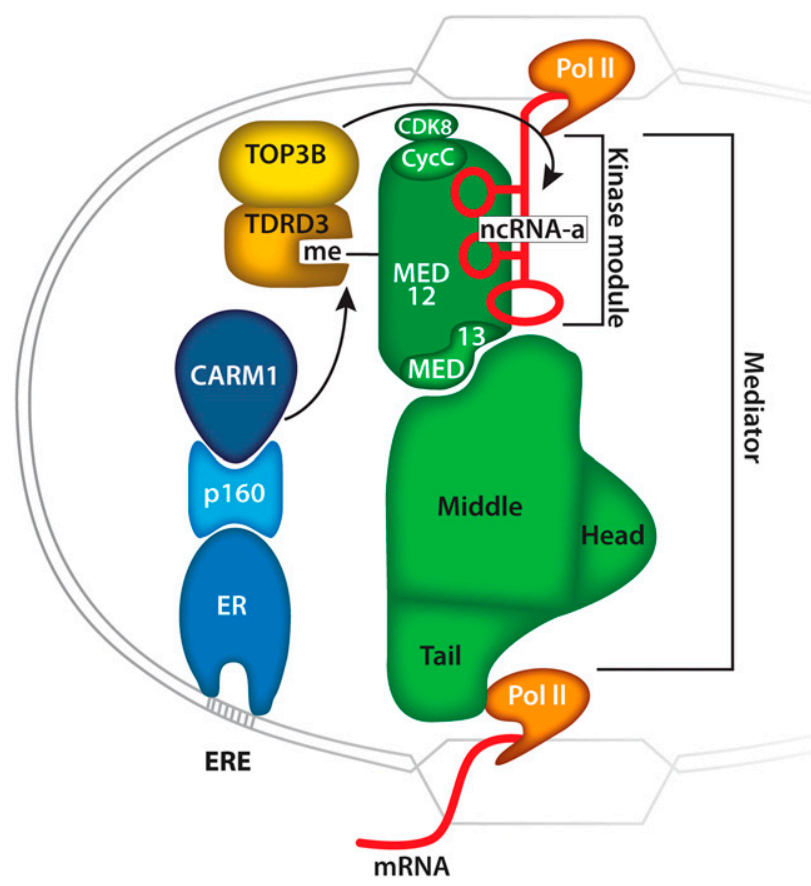

Figure 8. A model representing the regulation of MED12/ncRNA-a interactions by CARM1.

The sizes of the different proteins and protein complexes are not drawn to scale.

mutants were generated using a quick-change site-directed mutagenesis kit (Agilent). Biotinylated peptides encompassing residues 1,891-1,907 of the MED12 protein with unmodified, or asymmetrically dimethylated, Arg1899 were purchased from CPC Scientific.

\section{Cell lines}

The CARM1 WT and KO MEFs (Yadav et al, 2003), the tamoxifeninducible PRMT1 ${ }^{\mathrm{fl} /-}$ ER-Cre MEFs (Yu et al, 2009), and the tetracycline-inducible T-REx-CARM1-293 cell line (Cheng et al, 2007) have been described previously. The MCF-7-Tet-on-shCARM1 cell line was a gift from Wei Xu (University of Wisconsin). MCF-7, HeLa, and HEK293T cell lines were obtained from ATCC. To generate MED12 KO MCF-7 cell lines, a 20 bp guide sequence (GCCTCCCGATGTTTACCCTC) targeting the first exon of MED12 was selected using the online software tool, ZiFiT Targeter. Two complementary oligos (5'-CACCGCCTCCCGATGTTACCCTC-3' and 5'-AAACGAGGGTAAACATCGGGAGGC-3') containing the guide sequence were cloned into the LentiCRISPR vector, which also expresses Cas9 and a puromycin selectable marker for targeted KO. To generate ncRNA-a5 stable knockdown MCF-7 cell lines, SMARTvector lentiviral vector encoding nontargeting control-shRNA (VSC11707; Dharmacon) or SMARTVector lentiviral vectors encoding each of two distinct ncRNA-a5 (V3SH11246-245210427 and V3SH11246-245589794; Dharmacon) were used. Infected MCF-7 cells were selected using puromycin $(2 \mu \mathrm{g} / \mathrm{ml})$ to develop the lines. For MED12 KO, single cell clones were validated by Western blotting and confirmed by Sanger sequencing (using 5'-GAGGGATCCCTCGGCTTCCCTCGGTAGTTTC-3' and 5'-GAGGTCGACCCCTATTCATACCTTGGAACCC-3' primers). All cell lines were maintained in Dulbecco modified Eagle medium containing 10\% fetal bovine serum. 


\section{MS}

These experiments were performed at CST using an approach developed by John Rush for the identification of tyrosine phosphorylation sites (Rush et al, 2005). Briefly, proteins were extracted from the WT MEF cell line and digested with trypsin. The resulting complex peptide mixture was partitioned into three fractions by reversed-phase solid-phase extraction, and each fraction was treated with one of the four CARM1 substrate antibodies immobilized on agarose beads. After washing, peptides were eluted and analyzed by nanoflow LC-MS/MS. The resulting spectra were assigned to peptide sequences using the program Sequest. Lists of credible methylpeptide sequence assignments were generated.

\section{In vitro methylation assay}

The in vitro methylation reactions contained $1 \mu \mathrm{g}$ substrate (PABP1, $\mathrm{H} 3$, or MED12 peptides), $1 \mu \mathrm{g}$ recombinant GST-CARM1, and $1 \mu \mathrm{l}$ S-adenosyl-L-[methyl- ${ }^{3} \mathrm{H}$ ] methionine $(81.7 \mathrm{Ci} / \mathrm{mmol}$ from a $6.7 \mu \mathrm{M}$ stock solution, NET155001MC; PerkinElmer) in a final volume of $30 \mu \mathrm{l}$ PBS. The reactions were incubated at $30^{\circ} \mathrm{C}$ for $1.5 \mathrm{~h}$, and boiled in protein loading buffer for $5 \mathrm{~min}$. The samples were resolved by SDS-PAGE, transferred onto polyvinylidene difluoride membranes, treated with $E^{3}$ hance (6NE970C; PerkinElmer), and exposed to film for $1-3 \mathrm{~d}$ at $-80^{\circ} \mathrm{C}$.

\section{Peptide pull-down assay}

Biotinylated MED12 peptides $(20 \mu \mathrm{g})$ were immobilized on $20 \mu \mathrm{l}$ streptavidin agarose beads (16-126; Millipore) in $500 \mu$ lof mild lysis buffer (50 mM Tris-HCl pH 7.5, 150 mM NaCl, 0.1\% Nonidet P-40, 5 mM EDTA, $5 \mathrm{mM} \mathrm{EGTA}$, and $15 \mathrm{mM} \mathrm{MgCl}$ ) at $4^{\circ} \mathrm{C}$ for $2 \mathrm{~h}$. The beads were washed three times with mild lysis buffer and incubated with $4 \mu \mathrm{g}$ of GST-Tudor protein in $500 \mu \mathrm{l}$ mild lysis buffer at $4^{\circ} \mathrm{C}$ for $2 \mathrm{~h}$. After three washes with mild lysis buffer, the beads were boiled in protein loading buffer and subjected to Western blot analysis using $\alpha \mathrm{GST}$ antibody.

\section{IP}

HEK293T cells (90\% confluent) were transiently transfected with expression vectors encoding FLAG-tagged putative CARM1 substrates using Lipofectamine 2000 (Invitrogen). Cells (10 cm plate) were harvested after $24 \mathrm{~h}$, washed with ice-cold PBS and lysed in $1 \mathrm{ml}$ of radioimmunoprecipitation assay buffer $(25 \mathrm{mM}$ Tris- $\mathrm{HCl} \mathrm{pH}$ 7.6, $150 \mathrm{mM} \mathrm{NaCl}, 1 \%$ Nonidet P-40, 1\% sodium deoxycholate, $0.1 \%$ sodium dodecyl sulfate, and 2 mM EDTA) with protease inhibitor cocktail (Roche). The lysates were incubated with $40 \mu \mathrm{l}$ of anti-FLAG M2 affinity gel (A2220; Sigma-Aldrich) for $1 \mathrm{~h}$. The beads were washed three times with radioimmunoprecipitation assay buffer, eluted in protein loading buffer and analyzed by Western blotting. For the co-IP assays, cells (10 cm plate) were lysed in $1 \mathrm{ml}$ of mild lysis buffer and incubated with the specified antibodies. Immunoprecipitates were pulled down using protein $A / G$ ultralink resin (53132; Thermo Fisher Scientific) and the eluted proteins were analyzed by Western blotting. For the TDRD3-MED12 co-IP experiment, MCF7-tet-on-shCARM1 cells (Yang et al, 2010) were treated with $1 \mu \mathrm{g} / \mathrm{ml}$ of doxycycline for $6 \mathrm{~d}$ to knockdown endogenous CARM1 expression. Untreated parental cells were used as controls. Cells were lysed in buffer $A$ ( $10 \mathrm{mM}$ Hepes, $1.5 \mathrm{mM} \mathrm{MgCl} 2,10 \mathrm{mM} \mathrm{KCl}$, $0.5 \mathrm{mM}$ DTT, $0.05 \% \mathrm{NP} 40 \mathrm{pH}$ 7.9) supplemented with cocktails of protease inhibitor and phosphatase inhibitor (Pierce) for $10 \mathrm{~min}$ on ice. After centrifugation at $4^{\circ} \mathrm{C}$ at $845 \mathrm{~g}$ for $10 \mathrm{~min}$, the supernatant was removed and the pellet was resuspended in $387 \mu$ l of buffer $B$ (5 mM Hepes, $1.5 \mathrm{mM} \mathrm{MgCl}$, 0.2 mM EDTA, 0.5 mM DTT, 26\% glycerol [vol/vol] $\mathrm{pH} 7.9$ ) supplemented with $13 \mu \mathrm{l}$ of $4.6 \mathrm{M} \mathrm{NaCl}$ to give $150 \mathrm{mM} \mathrm{NaCl}$. After lysing on ice for $10 \mathrm{~min}$, brief sonication was applied to dissolve the pellet. Cell lysates were kept on ice for an additional $30 \mathrm{~min}$. After centrifugation at $24,000 \mathrm{~g}$ for $20 \mathrm{~min}$ at $4^{\circ} \mathrm{C}$, the supernatant was collected as nuclear extract for IP using antiTDRD3 antibody.

\section{ChIP and quantitative PCR}

Chromatin was harvested from MCF-7 cells as described previously (Iberg et al, 2008) and ChIP was performed using CARM1, MED12, and H3R17me2a antibodies. Using $2 \mu$ of ChIP DNA as the template, qPCR was performed on the ABI $7900 \mathrm{HT}$ fast real-time PCR system with primer sets against the specified genes (refer to Table S1). The data were analyzed using the Sequence Detection System software (ABI). The experimental cycle threshold $(\mathrm{Ct})$ was calibrated against the input product.

\section{ChIP-seq analysis}

\section{Mapping of reads}

Sequenced DNA reads were mapped to the human genome hg19 using bowtie (version 0.12.8) (Langmead et al, 2009) and only the reads that were mapped to a unique position were retained. 31-63 million reads were generated per sample. $80-97 \%$ reads were mapped to the human genome, with $59-71 \%$ uniquely mapped. To avoid PCR bias, for multiple reads that were mapped to the same genomic position, only one copy was retained for further analysis. In the final, 22-41 million reads were used in peak calling and downstream analyses.

\section{Peak calling and gene annotation}

The original peak calling for CARM1/MED12/H3R17me2a was performed by MACS (version 1.4.2) (Zhang et al, 2008) using total input DNA as the negative control. The window size was set as $300 \mathrm{bp}$ and the $P$-value cutoff was $1 \times 10^{-6}$. The peaks overlapping DAC blacklisted regions and Duke excluded regions downloaded from UCSC genome browser were removed. Then, the peaks from the three factors were merged (allowing at least $1 \mathrm{bp}$ overlap) to form a highly confident superset of peaks. For each peak from the superset, if it overlapped the peaks of one of the factors called at $P$-value $1 \times 10^{-4}$, it was marked as occupied by the corresponding factor. Each peak in the superset was assigned to the gene that has the closest transcription start site (TSS) to it. Then, the peak was classified by its location to the gene: upstream ( $-50 \mathrm{k}$ to $-5 \mathrm{k}$ from TSS), promoter ( $-5 k$ to $+0.5 k$ from TSS), exon, intron, the transcription end site (TES) ( $-0.5 k$ to $+5 k$ from TES), and downstream $(+5 \mathrm{k}$ to $+50 \mathrm{k}$ from TES). The gene list used to annotate the peaks is GENCODE release 19 (Harrow et al, 2012). 


\section{Landscape of ChIP-seq signal}

Each read was extended by 150 bp to its 3' end. The number of reads on each genomic position was rescaled to normalize the total number of mapped reads to 10 million and averaged over every $10 \mathrm{bp}$ window. The normalized values were displayed in the UCSC genome browser.

\section{Heatmap and average profile of ChIP-seq signal around peak center}

$10 \mathrm{kbp}$ upstream and $10 \mathrm{kbp}$ downstream from the center of each peak were subdivided into $250 \mathrm{bp}$ bins. For each ChIP-seq sample, the reads per million reads per kilobase values for each bin were calculated and normalized through z-score transformation to minimize the potential batch effect. The values were then averaged over all peaks to generate the average profile or plotted in heatmap by $\mathrm{R}$ function heatmap.2.

\section{Motif analysis}

Motif analysis including de novo motif searching by Multiple Em for Motif Elicitation (MEME), identifying centrally enriched motifs by CentriMo, and matching of identified motifs to known motifs by Tomtom were all performed by the program MEME-ChIP (Machanick \& Bailey, 2011) from MEME Suite (version 4.9.0). The sequences of -500 bp to +500 bp from the summit of peaks were taken as input. Motif Alignment \& Search Tool from MEME suite was used to identify the existence of motifs in peaks (the $P$-value cutoff was set at $1 \times 10^{-4}$ ).

\section{Published data sources}

H3K4me3, H3K27me3, and H3K27ac ChIP-seq data were downloaded from UCSC genome browser "Histone Modifications by ChIP-seq from ENCODE/Stanford/Yale/UCS/Harvard" track (http://genome. ucsc.edu/cgi-bin/hgFileUi?db=hg19\&g=wgEncodeSydhHistone). H3K4me1 ChIP-seq data were downloaded from Gene Expression Omnibus (GEO) dataset GSE57498. ER $\alpha$ ChIP-seq data were downloaded from GEO dataset GSE60270.

\section{Quantitative reverse transcription PCR (RT-qPCR)}

MCF-7-Tet-on-shCARM1 cells were untreated or treated with doxycycline $(1 \mu \mathrm{g} / \mathrm{ml})$ for $5 \mathrm{~d}$. The cells were then gently washed with PBS and transferred to phenol red-free DMEM supplemented with $10 \%$ charcoal dextran-stripped FBS. The cells were maintained in this media with or without doxycycline for $3 \mathrm{~d}$ and then treated with $50 \mathrm{nM}$ E2 for $4 \mathrm{~h}$. Total RNA was extracted using RNeasy Mini kit (74104; QIAGEN) and cDNA was synthesized using the Superscript III First-Strand Synthesis system (18080-051; Invitrogen). qPCR was then performed using primer sets against the specified genes (refer to Table S2). Data were analyzed using the Sequence Detection System software (ABI). The experimental Ct was calibrated against the $\beta$-actin control product, and the amount of sample product from Dox-treated cells relative to that of the control cells was determined using the DDCt method (onefold, 100\%).

\section{UV cross-linking-RNA IP (UV-RIP)}

UV cross-linking RIP was carried out as described previously (Hu et al, 2015) with modifications. Cells were washed with cold PBS and irradiated at $200 \mathrm{~mJ} / \mathrm{cm}^{2}$ at $254 \mathrm{~nm}$ (Ultraviolet crosslinker, from Ultra-Violet Products, Limited Liability Company). Nuclei were collected using Nuclei Isolation Kit (nuc101; Sigma-Aldrich) and resuspended in $1 \mathrm{ml}$ of RIP buffer (50 mM Tris- $\mathrm{HCl}$ pH 7.5, $150 \mathrm{mM}$ $\mathrm{NaCl}, 1 \% \mathrm{NP} 40,0.5 \%$ sodium deoxycholate, $1 \mathrm{mM} \mathrm{PMSF}, 400 \mathrm{U} / \mathrm{ml}$ RNase inhibitor, protease inhibitor cocktail). The nuclei were homogenized by sonication (10 cycles, $30 \mathrm{~s}$ "ON," 30 s "OFF") (diagenode; Bioruptor) and centrifuged at $13,000 \mathrm{rpm}$ for $10 \mathrm{~min}$ at $4^{\circ} \mathrm{C}$ to remove the insoluble material. $50 \mu \mathrm{l}$ of supernatant was saved as input. The rest of the supernatant was precleared by applying $15 \mu \mathrm{l}$ of Dynabeads $\mathrm{G}$ (Invitrogen) with $20 \mu \mathrm{g} / \mathrm{ml}$ yeast tRNA for $1 \mathrm{~h}$ at $4^{\circ} \mathrm{C}$. The precleared lysate was then incubated with $3 \mu \mathrm{g}$ of IgG or MED12 antibodies overnight. The lysate was centrifuged at 1,587 $\mathrm{g}$ for $10 \mathrm{~min}$ at $4^{\circ} \mathrm{C}$ to remove the insoluble material and incubated with triplewashed Dynabeads $\mathrm{G}$ beads $(20 \mu \mathrm{l})$ for $1 \mathrm{~h}$ at $4^{\circ} \mathrm{C}$. The beads were then washed thrice ( 5 min each wash) using washing buffer I ( $50 \mathrm{mM}$ Tris- $\mathrm{HCl}$ pH 7.5, $1 \mathrm{M} \mathrm{NaCl}$; 1\% NP40, 1\% Sodium Deoxycholate, 2 mM ribonucleoside vanadyl complex and washing buffer $\mathrm{II}(50 \mathrm{mM}$ Tris-HCl pH 7.5, $1 \mathrm{M} \mathrm{NaCl}, 1 \% \mathrm{NP} 40,1 \%$ Sodium Deoxycholate, $2 \mathrm{mM}$ VRC, $1 \mathrm{M}$ urea). The immunoprecipitated complexes were eluted using $2 \times 100 \mu$ lelution buffer (100 mM Tris- $\mathrm{HCl}$ at pH 7.0, 5 mM EDTA, $10 \mathrm{mM}$ DTT, 1\% SDS). Proteinase $\mathrm{K}(10 \mu \mathrm{g})$ was added into the $200 \mu \mathrm{l}$ RNA sample and incubated for $30 \mathrm{~min}$ at $55^{\circ} \mathrm{C}$. RNA was then extracted using RNeasy Mini Kit (74104; QIAGEN), digested with DNase I (QIAGEN), and used to synthesize CDNA using random hexamers (SuperScript III First-Strand Synthesis system 18080-051; Invitrogen) followed by qPCR analysis.

\section{Statistical Analysis}

All the data are reported as sample mean \pm SD. $t$ test was performed to determine the P-value for RT-qPCR and RIP-qPCR experiments. The asterisks shows values of statistical significance, where * stands for $P$-value ranges between 0.01 and $0.05 ;{ }^{* *}$ stands for $P$-value ranges between 0.001 and 0.01 , and ${ }^{* * *}$ stands for $P$-value less than 0.001 .

\section{Supplementary Information}

Supplementary Information is available at https://doi.org/10.26508/lsa. 201800117.

\section{Acknowledgements}

Stéphane Richard provided the CARM1 antibody (used in ChIP-seq experiments). This work was supported by National Institutes of Health grants GM126421 and ES023206, Cure on the Colorado fellowship (to V Vemulapalli), and City Federation of Women's Clubs Endowed Scholarship (to V Vemulapalli) J Shen was supported by CPRIT grant RP170002.

\section{Author Contributions}

D Cheng: conceptualization, data curation, formal analysis, investigation, methodology, project administration, and writing-original draft, review, and editing. 
V Vemulapalli: conceptualization, data curation, formal analysis, investigation, methodology, and writing-original draft, review, and editing.

Y Lu: data curation, formal analysis, investigation, and methodology. J Shen: validation and methodology.

S Aoyagi: data curation, formal analysis, investigation, and methodology. C) Fry: data curation, formal analysis, investigation, and methodology. Y Yang: data curation, formal analysis, investigation, and methodology. CE Foulds: validation, investigation, and methodology.

F Stossi: validation and methodology.

LS Treviño: validation and methodology.

MA Mancini: validation and methodology.

BW O'Malley: funding acquisition, investigation and methodology. CL Walker: funding acquisition, investigation and methodology.

TG Boyer: resources, investigation, and methodology.

MT Bedford: conceptualization, resources, data curation, formal analysis, supervision, funding acquisition, investigation, methodology, project administration, and writing-original draft, review, and editing.

\section{Conflict of Interest Statement}

MT Bedford is a cofounder of EpiCypher. Other authors declare that they have no conflict of interest. Deep sequencing data has been submitted to the NCBI-GEO accession number: GSE72848.

\section{References}

Allen BL, Taatjes DJ (2015) The mediator complex: A central integrator of transcription. Nat Rev Mol Cell Biol 16: 155-166. doi:10.1038/nrm3951

Bauer UM, Daujat S, Nielsen SJ, Nightingale K, Kouzarides T (2002) Methylation at arginine 17 of histone $\mathrm{H} 3$ is linked to gene activation. EMBO Rep 3: 39-44. doi:10.1093/embo-reports/kvf013

Bedford MT, Clarke SG (2009) Protein arginine methylation in mammals: Who, what, and why. Mol Cell 33: 1-13. doi:10.1016/j.molcel.2008.12.013

Boisvert FM, Cote J, Boulanger MC, Richard S (2003) A proteomic analysis of arginine-methylated protein complexes. Mol Cell Proteomics 2: 1319-1330. doi:10.1074/mcp.m300088-mcp200

Boriack-Sjodin PA, Jin L, Jacques SL, Drew A, Sneeringer C, Scott MP, Moyer MP, Ribich S, Moradei O, Copeland RA (2016) Structural insights into ternary complex formation of human CARM1 with various substrates. ACS Chem Biol 11: 763-771. doi:10.1021/acschembio.5b00773

Brahms H, Meheus L, de Brabandere V, Fischer U, Luhrmann R (2001) Symmetrical dimethylation of arginine residues in spliceosomal Sm protein B/B' and the Sm-like protein LSm4, and their interaction with the SMN protein. RNA 7: 1531-1542. doi:10.1017/s135583820101442x

Carascossa S, Dudek P, Cenni B, Briand PA, Picard D (2010) CARM1 mediates the ligand-independent and tamoxifen-resistant activation of the estrogen receptor alpha by cAMP. Genes Dev 24: 708-719. doi:10.1101/ gad. 568410

Carroll JS, Meyer CA, Song J, Li W, Geistlinger TR, Eeckhoute J, Brodsky AS, Keeton EK, Fertuck KC, Hall GF, et al (2006) Genome-wide analysis of estrogen receptor binding sites. Nat Genet 38: 1289-1297. doi:10.1038/ ng1901

Ceschin DG, Walia M, Wenk SS, Duboe C, Gaudon C, Xiao Y, Fauquier L, Sankar M, Vandel L, Gronemeyer H (2011) Methylation specifies distinct estrogen-induced binding site repertoires of CBP to chromatin. Genes Dev 25: 1132-1146. doi:10.1101/gad.619211
Chen D, Huang SM, Stallcup MR (2000) Synergistic, p160 coactivatordependent enhancement of estrogen receptor function by CARM1 and p300. J Biol Chem 275: 40810-40816. doi:10.1074/jbc.m005459200

Chen D, Ma H, Hong H, Koh SS, Huang SM, Schurter BT, Aswad DW, Stallcup MR (1999) Regulation of transcription by a protein methyltransferase. Science 284: 2174-2177. doi:10.1126/science.284.5423.2174

Cheng D, Bedford MT (2011) Xenoestrogens regulate the activity of arginine methyltransferases. Chembiochem 12: 323-329. doi:10.1002/ cbic.201000522

Cheng D, Cote J, Shaaban S, Bedford MT (2007) The arginine methyltransferase CARM1 regulates the coupling of transcription and mRNA processing. Mol Cell 25: 71-83. doi:10.1016/j.molcel.2006.11.019

Cheng D, Vemulapalli V, Bedford MT (2012) Methods applied to the study of protein arginine methylation. Methods Enzymol 512: 71-92. doi:10.1016/b978-0-12-391940-3.00004-4

Cote J, Richard S (2005) Tudor domains bind symmetrical dimethylated arginines. J Biol Chem 280: 28476-28483. doi:10.1074/jbc.m414328200

Coughlan N, Thillainadesan G, Andrews J, Isovic M, Torchia J (2013) betaEstradiol-dependent activation of the JAK/STAT pathway requires p/CIP and CARM1. Biochim Biophys Acta 1833: 1463-1475. doi:10.1016/j. bbamcr.2013.02.009

Covic M, Hassa PO, Saccani S, Buerki C, Meier NI, Lombardi C, Imhof R, Bedford MT, Natoli G, Hottiger MO (2005) Arginine methyltransferase CARM1 is a promoter-specific regulator of NF-kappaB-dependent gene expression. EMBO J 24: 85-96. doi:10.1038/sj.emboj.7600500

Dhar S, Vemulapalli V, Patananan AN, Huang GL, Di Lorenzo A, Richard S, Comb MJ, Guo A, Clarke SG, Bedford MT (2013) Loss of the major Type I arginine methyltransferase PRMT1 causes substrate scavenging by other PRMTs. Sci Rep 3: 1311. doi:10.1038/srep01311

El Messaoudi S, Fabbrizio E, Rodriguez C, Chuchana P, Fauquier L, Cheng D, Theillet C, Vandel L, Bedford MT, Sardet C (2006) Coactivatorassociated arginine methyltransferase 1 (CARM1) is a positive regulator of the Cyclin E1 gene. Proc Natl Acad Sci USA 103: 13351-13356. doi:10.1073/pnas.0605692103

Fauquier L, Duboe C, Jore C, Trouche D, Vandel L (2008) Dual role of the arginine methyltransferase CARM1 in the regulation of c-Fos target genes. FASEB / 22: 3337-3347. doi:10.1096/fj.07-104604

Feng Q, Yi P, Wong J, O'Malley BW (2006) Signaling within a coactivator complex: Methylation of SRC-3/AIB1 is a molecular switch for complex disassembly. Mol Cell Biol 26: 7846-7857. doi:10.1128/ mcb.00568-06

Ford DJ, Dingwall AK (2015) The cancer COMPASS: Navigating the functions of MLL complexes in cancer. Cancer Genet 208: 178-191. doi:10.1016/j. cancergen.2015.01.005

Frankel A, Yadav N, Lee J, Branscombe TL, Clarke S, Bedford MT (2002) The novel human protein arginine $\mathrm{N}$-methyltransferase PRMT6 is a nuclear enzyme displaying unique substrate specificity. I Biol Chem 277: 3537-3543. doi:10.1074/jbc.m108786200

Friesen WJ, Massenet S, Paushkin S, Wyce A, Dreyfuss G (2001) SMN, the product of the spinal muscular atrophy gene, binds preferentially to dimethylarginine-containing protein targets. Mol Cell 7: 1111-1117. doi:10.1016/s1097-2765(01)00244-1

Frietze S, Lupien M, Silver PA, Brown M (2008) CARM1 regulates estrogenstimulated breast cancer growth through up-regulation of E2F1. Cancer Res 68: 301-306. doi:10.1158/0008-5472.can-07-1983

Fujiwara T, Mori Y, Chu DL, Koyama Y, Miyata S, Tanaka H, Yachi K, Kubo T, Yoshikawa $\mathrm{H}$, Tohyama M (2006) CARM1 regulates proliferation of PC12 cells by methylating HuD. Mol Cell Biol 26: 2273-2285. doi:10.1128/ mcb.26.6.2273-2285.2006

Gao WW, Xiao RQ, Zhang WJ, Hu YR, Peng BL, Li WJ, He YH, Shen HF, Ding JC, Huang QX, et al (2018) JMJD6 licenses ERalpha-dependent enhancer and coding gene activation by modulating the recruitment of the 
CARM1/MED12 co-activator complex. Mol Cell 70: 340-357.e8. doi:10.1016/j.molcel.2018.03.006

Gayatri S, Bedford MT (2014) Readers of histone methylarginine marks. Biochim Biophys Acta 1839: 702-710. doi:10.1016/j.bbagrm.2014.02.015

Gayatri S, Cowles MW, Vemulapalli V, Cheng D, Sun ZW, Bedford MT (2016) Using oriented peptide array libraries to evaluate methylargininespecific antibodies and arginine methyltransferase substrate motifs. Sci Rep 6: 28718. doi:10.1038/srep28718

Geoghegan V, Guo A, Trudgian D, Thomas B, Acuto O (2015) Comprehensive identification of arginine methylation in primary $T$ cells reveals regulatory roles in cell signalling. Nat Commun 6: 6758. doi:10.1038/ ncomms7758

Guo A, Gu H, Zhou J, Mulhern D, Wang Y, Lee KA, Yang V, Aguiar M, Kornhauser J, Jia $X$, et al (2014) Immunoaffinity enrichment and mass spectrometry analysis of protein methylation. Mol Cell Proteomics 13: 372-387. doi:10.1074/mcp.0113.027870

Harrow J, Frankish A, Gonzalez JM, Tapanari E, Diekhans M, Kokocinski F, Aken BL, Barrell D, Zadissa A, Searle S, et al (2012) GENCODE: The reference human genome annotation for the ENCODE project. Genome Res 22: 1760-1774. doi:10.1101/gr.135350.111

Hein K, Mittler G, Cizelsky W, Kuhl M, Ferrante F, Liefke R, Berger IM, Just S, Strang JE, Kestler HA, et al (2015) Site-specific methylation of Notch1 controls the amplitude and duration of the Notch1 response. Sci Signal 8: ra30. doi:10.1126/scisignal.2005892

Hsieh CL, Fei T, Chen Y, Li T, Gao Y, Wang X, Sun T, Sweeney C), Lee GS, Chen S, et al (2014) Enhancer RNAs participate in androgen receptor-driven looping that selectively enhances gene activation. Proc Natl Acad Sci USA 111: 7319-7324. doi:10.1073/pnas.1324151111

Hu SB, Xiang JF, Li X, Xu Y, Xue W, Huang M, Wong CC, Sagum CA, Bedford MT, Yang $\mathrm{L}$, et al (2015) Protein arginine methyltransferase CARM1 attenuates the paraspeckle-mediated nuclear retention of mRNAs containing IRAlus. Genes Dev 29: 630-645. doi:10.1101/gad.257048.114

Huang S, Holzel M, Knijnenburg T, Schlicker A, Roepman P, McDermott U, Garnett M, Grernrum W, Sun C, Prahallad A, et al (2012) MED12 controls the response to multiple cancer drugs through regulation of TGF-beta receptor signaling. Cell 151: 937-950. doi:10.1016/j.cell.2012.10.035

Iberg AN, Espejo A, Cheng D, Kim D, Michaud-Levesque J, Richard S, Bedford MT (2008) Arginine methylation of the histone H3 tail impedes effector binding. J Biol Chem 283: 3006-3010. doi:10.1074/jbc.c700192200

Ito T, Yadav N, Lee J, Furumatsu T, Yamashita S, Yoshida K, Taniguchi N, Hashimoto M, Tsuchiya M, Ozaki T, et al (2009) Arginine methyltransferase CARM1/PRMT4 regulates endochondral ossification. BMC Dev Biol 9: 47. doi:10.1186/1471-213x-9-47

Kawabe Y, Wang YX, McKinnell IW, Bedford MT, Rudnicki MA (2012) Carm1 regulates Pax7 transcriptional activity through $M L L 1 / 2$ recruitment during asymmetric satellite stem cell divisions. Cell Stem Cell 11: 333-345. doi:10.1016/j.stem.2012.07.001

Kim D, Lee J, Cheng D, Li J, Carter C, Richie E, Bedford MT (2010) Enzymatic activity is required for the in vivo functions of CARM1. J Biol Chem 285: 1147-1152. doi:10.1074/jbc.m109.035865

Kim J, Daniel J, Espejo A, Lake A, Krishna M, Xia L, Zhang Y, Bedford MT (2006) Tudor, MBT and chromo domains gauge the degree of lysine methylation. EMBO Rep 7: 397-403. doi:10.1038/sj.embor.7400625

Kim J, Lee J, Yadav N, Wu Q, Carter C, Richard S, Richie E, Bedford MT (2004) Loss of CARM1 results in hypomethylation of thymocyte cyclic AMPregulated phosphoprotein and deregulated early $T$ cell development. J Biol Chem 279: 25339-25344. doi:10.1074/jbc.m402544200

Kim TK, Shiekhattar R (2015) Architectural and functional commonalities between enhancers and promoters. Cell 162: 948-959. doi:10.1016/j. cell.2015.08.008

Kleinschmidt MA, Streubel G, Samans B, Krause M, Bauer UM (2008) The protein arginine methyltransferases CARM1 and PRMT1 cooperate in gene regulation. Nucleic Acids Res 36: 3202-3213. doi:10.1093/nar/ gkn166

Kowenz-Leutz E, Pless O, Dittmar G, Knoblich M, Leutz A (2010) Crosstalk between C/EBPbeta phosphorylation, arginine methylation, and SWI/ SNF/mediator implies an indexing transcription factor code. EMBO 29: 1105-1115. doi:10.1038/emboj.2010.3

Lai F, Orom UA, Cesaroni M, Beringer M, Taatjes DJ, Blobel GA, Shiekhattar R (2013) Activating RNAs associate with mediator to enhance chromatin architecture and transcription. Nature 494: 497-501. doi:10.1038/ nature11884

Langmead B, Trapnell C, Pop M, Salzberg SL (2009) Ultrafast and memoryefficient alignment of short DNA sequences to the human genome. Genome Biol 10: R25. doi:10.1186/gb-2009-10-3-r25

Lee J, Bedford MT (2002) PABP1 identified as an arginine methyltransferase substrate using high-density protein arrays. EMBO Rep 3: 268-273. doi:10.1093/embo-reports/kvf052

Lee JE, Wang C, Xu S, Cho YW, Wang L, Feng X, Baldridge A, Sartorelli V, Zhuang L, Peng W, et al (2013) H3K4 mono- and di-methyltransferase MLL4 is required for enhancer activation during cell differentiation. Elife 2: e01503. doi:10.7554/elife.01503

Lee YH, Coonrod SA, Kraus WL, Jelinek MA, Stallcup MR (2005) Regulation of coactivator complex assembly and function by protein arginine methylation and demethylimination. Proc Natl Acad Sci USA 102: 3611-3616. doi:10.1073/pnas.0407159102

Li H, Park S, Kilburn B, Jelinek MA, Henschen-Edman A, Aswad DW, Stallcup MR, Laird-Offringa IA (2002) Lipopolysaccharide-induced methylation of HuR, an mRNA-stabilizing protein, by CARM1. Coactivatorassociated arginine methyltransferase. J Biol Chem 277: 44623-44630. doi:10.1074/jbc.m206187200

Lupien M, Eeckhoute J, Meyer CA, Krum SA, Rhodes DR, Liu XS, Brown M (2009) Coactivator function defines the active estrogen receptor alpha cistrome. Mol Cell Biol 29: 3413-3423. doi:10.1128/ mcb.00020-09

Machanick P, Bailey TL (2011) MEME-ChIP: Motif analysis of large DNA datasets. Bioinformatics 27: 1696-1697. doi:10.1093/bioinformatics/ btr189

Naeem H, Cheng D, Zhao Q, Underhill C, Tini M, Bedford MT, Torchia J (2007) The activity and stability of the transcriptional coactivator $\mathrm{p} / \mathrm{CIP} / \mathrm{SRC}$ 3 are regulated by CARM1-dependent methylation. Mol Cell Biol 27: 120-134. doi:10.1128/mcb.00815-06

O'Brien KB, Alberich-Jorda M, Yadav N, Kocher O, Diruscio A, Ebralidze A, Levantini E, Sng NJ, Bhasin M, Caron T, et al (2010) CARM1 is required for proper control of proliferation and differentiation of pulmonary epithelial cells. Development 137: 2147-2156. doi:10.1242/ dev.037150

Ong SE, Mittler G, Mann M (2004) Identifying and quantifying in vivo methylation sites by heavy methyl SILAC. Nat Methods 1: 119-126. doi:10.1038/nmeth715

Orom UA, Derrien T, Beringer M, Gumireddy K, Gardini A, Bussotti G, Lai F, Zytnicki M, Notredame C, Huang Q, et al (2010) Long noncoding RNAs with enhancer-like function in human cells. Cell 143: 46-58. doi:10.1016/j.cell.2010.09.001

Papadopoulou T, Kaymak A, Sayols S, Richly H (2016) Dual role of Med12 in PRC1-dependent gene repression and ncRNA-mediated transcriptional activation. Cell Cycle: 1-15. doi:10.1080/15384101.2016.1175797

Rae JM, Johnson MD, Scheys JO, Cordero KE, Larios JM, Lippman ME (2005) GREB 1 is a critical regulator of hormone dependent breast cancer growth. Breast Cancer Res Treat 92: 141-149. doi:10.1007/s10549-0051483-4

Rush J, Moritz A, Lee KA, Guo A, Goss VL, Spek EJ, Zhang H, Zha XM, Polakiewicz RD, Comb MJ (2005) Immunoaffinity profiling of tyrosine phosphorylation in cancer cells. Nat Biotechnol 23: 94-101. doi:10.1038/nbt1046 
Shimbo T, Du Y, Grimm SA, Dhasarathy A, Mav D, Shah RR, Shi H, Wade PA (2013) MBD3 localizes at promoters, gene bodies and enhancers of active genes. PLoS Genet 9: e1004028. doi:10.1371/journal. pgen.1004028

Shin HJ, Kim H, Oh S, Lee JG, Kee M, Ko HJ, Kweon MN, Won KJ, Baek SH (2016) AMPK-SKP2-CARM1 signalling cascade in transcriptional regulation of autophagy. Nature 534: 553-557. doi:10.1038/nature18014

Shishkova E, Zeng H, Liu F, Kwiecien NW, Hebert AS, Coon JJ, Xu W (2017) Global mapping of CARM1 substrates defines enzyme specificity and substrate recognition. Nat Commun 8: 15571. doi:10.1038/ ncomms 15571

Siaw GE, Liu IF, Lin PY, Been MD, Hsieh TS (2016) DNA and RNA topoisomerase activities of Top3beta are promoted by mediator protein Tudor domain-containing protein 3. Proc Natl Acad Sci USA 113: E5544-E5551. doi:10.1073/pnas.1605517113

Sims RJ 3rd, Rojas LA, Beck D, Bonasio R, Schuller R, Drury WJ 3rd, Eick D, Reinberg D (2011) The C-terminal domain of RNA polymerase II is modified by site-specific methylation. Science 332: 99-103. doi:10.1126/science.1202663

Step SE, Lim HW, Marinis JM, Prokesch A, Steger DJ, You SH, Won KJ, Lazar MA (2014) Anti-diabetic rosiglitazone remodels the adipocyte transcriptome by redistributing transcription to PPARgamma-driven enhancers. Genes Dev 28: 1018-1028. doi:10.1101/gad.237628.114

Stoll G, Pietilainen OP, Linder B, Suvisaari J, Brosi C, Hennah W, Leppa V, Torniainen M, Ripatti S, Ala-Mello S, et al (2013) Deletion of TOP3beta, a component of FMRP-containing mRNPs, contributes to neurodevelopmental disorders. Nat Neurosci 16: 1228-1237. doi:10.1038/nn.3484

Streubel G, Bouchard C, Berberich H, Zeller MS, Teichmann S, Adamkiewicz J, Muller R, Klempnauer KH, Bauer UM (2013) PRMT4 is a novel coactivator of C-Myb-dependent transcription in haematopoietic cell lines. PLoS Genet 9: e1003343. doi:10.1371/journal.pgen.1003343

Teferedegne B, Green MR, Guo Z, Boss JM (2006) Mechanism of action of a distal NF-kappaB-dependent enhancer. Mol Cell Biol 26: 5759-5770. doi:10.1128/mcb.00271-06

Thandapani P, O'Connor TR, Bailey TL, Richard S (2013) Defining the RGG/RG motif. Mol Cell 50: 613-623. doi:10.1016/j.molcel.2013.05.021

Traunmuller L, Bornmann C, Scheiffele P (2014) Alternative splicing coupled nonsense-mediated decay generates neuronal cell type-specific expression of SLM proteins. J Neurosci 34: 16755-16761. doi:10.1523/ jneurosci.3395-14.2014

Uhlmann T, Geoghegan VL, Thomas B, Ridlova G, Trudgian DC, Acuto O (2012) A method for large-scale identification of protein arginine methylation. Mol Cell Proteomics 11: 1489-1499. doi:10.1074/mcp. m112.020743

van Haren MJ, Marechal N, Troffer-Charlier N, Cianciulli A, Sbardella G, Cavarelli J, Martin NI (2017) Transition state mimics are valuable mechanistic probes for structural studies with the arginine methyltransferase CARM1. Proc Natl Acad Sci USA 114: 3625-3630. doi:10.1073/pnas.1618401114

Wang KC, Yang YW, Liu B, Sanyal A, Corces-Zimmerman R, Chen Y, Lajoie BR, Protacio A, Flynn RA, Gupta RA, et al (2011) A long noncoding RNA maintains active chromatin to coordinate homeotic gene expression. Nature 472: 120-124. doi:10.1038/nature09819

Wang L, Zeng H, Wang Q, Zhao Z, Boyer TG, Bian X, Xu W (2015) MED12 methylation by CARM1 sensitizes human breast cancer cells to chemotherapy drugs. Sci Adv 1: e1500463. doi:10.1126/sciadv.1500463
Wang L, Zhao Z, Meyer MB, Saha S, Yu M, Guo A, Wisinski KB, Huang W, Cai W, Pike JW, et al (2014) CARM1 methylates chromatin remodeling factor BAF155 to enhance tumor progression and metastasis. Cancer Cell 25: 21-36. doi:10.1016/j.ccr.2013.12.007

Wong MM, Guo C, Zhang J (2014) Nuclear receptor corepressor complexes in cancer: Mechanism, function and regulation. Am J Clin Exp Urol 2: 169-187. AJCEU0002556

Wu Q, Bruce AW, Jedrusik A, Ellis PD, Andrews RM, Langford CF, Glover DM, Zernicka-Goetz M (2009) CARM1 is required in embryonic stem cells to maintain pluripotency and resist differentiation. Stem Cells 27: 2637-2645. doi:10.1002/stem.131

Xu D, Shen W, Guo R, Xue Y, Peng W, Sima J, Yang J, Sharov A, Srikantan S, Fox D 3rd, et al (2013) Top3beta is an RNA topoisomerase that works with fragile $X$ syndrome protein to promote synapse formation. Nat Neurosci 16: 1238-1247. doi:10.1038/nn.3479

Xu W, Cho H, Kadam S, Banayo EM, Anderson S, Yates JR 3rd, Emerson BM, Evans RM (2004) A methylation-mediator complex in hormone signaling. Genes Dev 18: 144-156. doi:10.1101/gad.1141704

Yadav N, Cheng D, Richard S, Morel M, Iyer VR, Aldaz CM, Bedford MT (2008) CARM1 promotes adipocyte differentiation by coactivating PPARgamma. EMBO Rep 9: 193-198. doi:10.1038/sj.embor.7401151

Yadav N, Lee J, Kim J, Shen J, Hu MC, Aldaz CM, Bedford MT (2003) Specific protein methylation defects and gene expression perturbations in coactivator-associated arginine methyltransferase 1-deficient mice. Proc Natl Acad Sci USA 100: 6464-6468. doi:10.1073/pnas.1232272100

Yang Y, Bedford MT (2013) Protein arginine methyltransferases and cancer Nat Rev Cancer 13: 37-50. doi:10.1038/nrc3409

Yang Y, Hadjikyriacou A, Xia Z, Gayatri S, Kim D, Zurita-Lopez C, Kelly R, Guo A, Li W, Clarke SG, et al (2015) PRMT9 is a type II methyltransferase that methylates the splicing factor SAP145. Nat Commun 6: 6428. doi: $10.1038 /$ ncomms7428

Yang Y, Lu Y, Espejo A, Wu J, Xu W, Liang S, Bedford MT (2010) TDRD3 is an effector molecule for arginine-methylated histone marks. Mol Cell 40: 1016-1023. doi:10.1016/j.molcel.2010.11.024

Yang Y, McBride KM, Hensley S, Lu Y, Chedin F, Bedford MT (2014) Arginine methylation facilitates the recruitment of TOP3B to chromatin to prevent R loop accumulation. Mol Cell 53: 484-497. doi:10.1016/j. molcel.2014.01.011

Yu Z, Chen T, Hebert J, Li E, Richard S (2009) A mouse PRMT1 null allele defines an essential role for arginine methylation in genome maintenance and cell proliferation. Mol Cell Biol 29: 2982-2996. doi:10.1128/ mcb.00042-09

Zeng H, Wu J, Bedford MT, Sbardella G, Hoffmann FM, Bi K, Xu W (2013) A TRFRET-based functional assay for screening activators of CARM1. Chembiochem 14: 827-835. doi:10.1002/cbic.201300029

Zhang Y, Liu T, Meyer CA, Eeckhoute J, Johnson DS, Bernstein BE, Nusbaum C, Myers RM, Brown M, Li W, et al (2008) Model-based analysis of ChIPseq (MACS). Genome Biol 9: R137. doi:10.1186/gb-2008-9-9-r137

Zhao HY, Zhang YJ, Dai H, Zhang Y, Shen YF (2011) CARM1 mediates modulation of Sox2. PLoS One 6: e27026. doi:10.1371/journal.pone.0027026

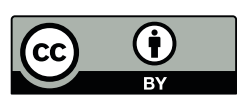

License: This article is available under a Creative Commons License (Attribution 4.0 International, as described at https://creativecommons.org/ licenses/by/4.0/). 